\title{
Exosomal Micro RNA-107 Reverses \\ Chemotherapeutic Drug Resistance of Gastric Cancer Cells Through HMGA2/mTOR/P-gp Pathway
}

\section{Lu Jiang}

Henan University of Traditional Chinese Medicine

\section{Yan Zhang}

Henan University of Traditional Chinese Medicine

Linghui Guo

Henan University of Traditional Chinese Medicine

Chaoyang Liu

Henan University of Traditional Chinese Medicine

Weihong Ren ( $\nabla$ ren_weihong@163.com )

The First Affiliated Hospital of Henan University of Traditional Chinese Medicine

\section{Research Article}

Keywords: Gastric cancer, Reverse drug resistance, exosomal miR-107, HMGA2/mTOR/P-gp

Posted Date: June 2nd, 2021

DOI: https://doi.org/10.21203/rs.3.rs-540926/v1

License: (c) (i) This work is licensed under a Creative Commons Attribution 4.0 International License. Read Full License 


\section{Exosomal micro RNA-107 reverses chemotherapeutic drug resistance of gastric cancer cells through HMGA2/mTOR/P-gp pathway}

Lu Jiang ${ }^{1}$, Yan Zhang ${ }^{1}$, Linghui Guo ${ }^{1}$, Chaoyang Liu ${ }^{1}$, Weihong Ren ${ }^{2 *}$

${ }^{1}$ Henan University of Traditional Chinese Medicine, 156 Jinshui East Road, Zhengzhou 450046, China. ${ }^{2}$ Department of Clinical Laboratory, The First Affiliated Hospital of Henan University of Traditional Chinese Medicine, 19 Renmin Road, Zhengzhou 450000, China.

*Corresponding author, E-mail: ren_weihong@163.com

\section{Abstract}

Background: RNA cargo in exosomes, especially microRNAs (miRNAs), play an important role in the chemotherapy drug resistance of human cancers. However, the role and mechanism of exosomal miR-107 on multidrug resistance of gastric cancer cells was still not clear. In this study, we sought to explore whether exosomal miR-107 could reverse the resistance of gastric cancer cells to the chemotherapy drugs.

Methods: We extracted exosomes from sensitive (SGC-7901, MGC-803) and resistant (SGC-7901/5-FU) gastric cancer cells by ultracentrifugation and the isolated exosomes were identified using transmission electron microscopy (TEM) and dynamic light scattering analysis (DLS). The expression of miR-107 and high mobility group A2 (HMGA2) were detected by real-time quantitative PCR (RT-qPCR). MTT assay was used to investigate the effect of exosomes on gastric cancer cells growth in vitro. The uptake of exosomes by recipient cells were observed using a fluorescence microscope. The predicted target relationship between 
miR-107 and HMGA2 was verified by gauss-luciferase reporter assay. The expression of HMGA2, p-mTOR/mTOR, P-gp and other exosomal indicated marker proteins were detected by western blot.

Results: Our results indicated that the isolated exosomes were demostrated typically cup-like lipid bilayer membrans structure. SGC-7901/5-FU cells were cross-resistant to chemotherapy drug cisplatin (DDP), and the sensitive cells-secreted exosomes drastically reversed the resistance of the resistant gastric cells to the chemotherapeutic drugs, which was verificated by exosomal inhibitor GW4896. Mechanistically, the reversal effect were mainly mediated by exosome-secreted miR-107 through downregulating the expression of targert molecular HMGA2, and inhibiting HMGA2/mTOR/P-gp pathway, which were proofed by luciferase reporter assay and rescue assay.

Conclusions: These findings demonstrated that exosome-transmitted miR-107 significantly enhanced the sensitivity of resistant gastric cancer cells to chemotherapeutic agents by mediating the HMGA2/mTOR/P-gp axis and appling exosomal miR-107 may be a novel target in gastric cancers treatment.

Keywords : Gastric cancer, Reverse drug resistance, exosomal miR-107, HMGA2/mTOR/P-gp 


\section{Background}

Gastric cancer (GC) is the fifth most common malignant tumor in the world and the third leading cause of cancer-related deaths, posing a serious threat to human life and health [1]. Due to the lack of effective biomolecular markers, GC is usually diagnosed at an advanced stage, and its 5 -year survival rate is about $20-30 \%[2,3]$. Various factors including genetics, epigenetics and environment could affect the occurrence and progression of GC [4]. At the present stage, there is still lacking of effective treatment methods in the clinical treatment of advanced gastric cancer, although targeted therapy or a combination of targeted therapy and chemotherapy could improve the treatment effect to a certain extent, surgery and chemotherapy are still the main method of treatment. The chemotherapy drugs 5-Fluorouracil, cisplatin, doxorubicin and paclitaxel were commonly used for GC treatment, which inevitably leaded to chemotherapy drug resistance [5]. Therefore, exploring the mechanism of drug resistance in GC are urgently needed clinically, and would provides a reference for clinical treatment.

Exosomes are a class of extracellular vesicles with $30-150 \mathrm{~nm}$ in diameter, and have a lipid bilayer structure, which similar to cell membranes. The membrane contained a variety of proteins (CD9, CD63, CD81 and integrins, etc.) and lipids (ceramide, phosphatidylethanolamine, phosphatidylserine, etc.), and also the inside of exosomes also included a 
variety of nucleic acids (mRNA, miRNA, LncRNA, circRNA and DNA) and proteins (TSG101, Alix, Hsc70 and Hsp90, etc.) [6]. Exosomes could transport a variety of biologically active molecules (such as nucleic acids, lipids, and proteins) to the recipient cells by binding to the recipient cells, which mediated the information exchange of between cells, and regulated a variety of cellular physiological and pathological processes [7]. Especially, dut to the lipid membranes protection, the exosomal miRNAs excluded from being damaged by cellular environment, many studies have reported cancer cells-drived exosomal miRNAs played important roles in mediating cellular immune response and tumor angiogenesis, drug resistance and metastasis $[8,9]$. Some literatures demostrated that variety of exosomal miRNAs could regulate chemotherapy resistance of cancer cells $[10,11]$.

MicroRNA-107 was a new non-coding RAN researched in recent years, several researches have illustrated that miRNA-107 played an important role in various diseases process, such as cancers, alzheimer's disease, human osteoarthritis [12-14]. Although there were many studies showed that the sensitivity of non-small cell lung cancer cells and breast cancer cells to chemotherapy drug paclitaxel could be regulated by miRNA-107 [15,16], also the expression level of miRNA-107 might be a effective biomarker for poor prognosis of GC patients [17], whether exosomal miR-107 also had a regulatory effect on multidrug resistance of 
cancer cells has not been elucidated, and the detailed underlying mechanisms of how exosomal miR-107 regulates the sensitivity of cancer cells to the chemotherapeutic drugs remain largely unknown. In this study, we sought to explore the effects of exosomal miR-107 on chemotherapeutic drug-resistance and found that exosomal miR-107 extracted from sensitive GC cells could increase the sensitivity of drugs resistance GC cells. We also identified the target molecular of exosomal miR-107 was HMGA2, which was a small non-histone nuclear protein, or a framework transcription factor, could change the gene DNA conformation, or directly interact with related proteins, then enhance or inhibit the transcriptional activity of the genes through binding to the chromatin enriched with AT sequences via its AT hook structure [18]. Also, some studies showed that mTOR signaling could regulate the drug resistance of tumor cells by regulating the expression of P-glycoprotein (P-gp) [19,20], Our results showed that the molecular mechanism underlying the reversal role of exosomal miR-107 by regulating the expression of target molecular HMGA2, the activity of mTOR and the expression of P-gp.

\section{Materials and methods}

\section{Cell viability analysis}

5-FU sensitive/resistant human gastric cancer cell line SGC-7901 (both from Huiying BioTech), MGC-803 human gastric cancer and HEK 
293T cell lines (both from Beina BioTech), were maintained in RPMI-1640 and DMEM-H medium (Sigma-Aldrich), supplemented with $10 \% \mathrm{FBS}$ at $37^{\circ} \mathrm{C}$ in a humidified atmosphere with $5 \% \mathrm{CO} 2$, respectively. Different concentrations of 5-FU or cisplatin (Meilun BioTech) were used to treat the cells. After $48 \mathrm{~h}$ incubation, cells were subjected to MTT analysis and the absorbance at $570 \mathrm{~nm}$ was recorded by a Spectra Max i3 microplate reader (Molecular Devices Corp., Sunnyvale, CA, USA).

\section{Exosome isolation}

The SGC-7901 and SGC-7901/5-FU GC cells were cultured in 1640 medium containing 10\% exosome-free fetal bovine serum (FBS), and exosomes were extracted by ultracentrifugation method. the collected cell supernatant was centrifuged at $300 \times \mathrm{g}$ for $10 \mathrm{~min}, 2000 \times \mathrm{g}$ for $20 \mathrm{~min}$, $10,000 \times \mathrm{g}$ for $20 \mathrm{~min}$, respectively. Then was filtered by a $0.22 \mu \mathrm{M}$ filter and centrifuged at $3,500 \times \mathrm{g}$ for $5 \mathrm{~min}$ in ultrafiltration tubes. The concentrated supernatant were performed gradient centrifugation: 80,000 $\times \mathrm{g} / 40 \mathrm{~min}, 80,000 \times \mathrm{g} / 80 \mathrm{~min}, 110,000 \times \mathrm{g} / 40 \mathrm{~min}, 110,000 \times \mathrm{g} / 80$ $\min , 110,000 \times \mathrm{g} / 120 \min , 140,000 \times \mathrm{g} / 40 \mathrm{~min}, 140,000 \times \mathrm{g} / 80$

$\min , 140,000 \times \mathrm{g} / 120 \mathrm{~min}$ at $4^{\circ} \mathrm{C}$. Finally, exosomes were washed and resuspended by PBS. The diameter of exosomes was detected by DLS as described below. The concentration of exosomes was measured by BCA protein assay kit.

\section{Transmission electron microscopy}


The morphology and size of exosomes was observed by a transmission electron microscopy (JEM-1400, Tokyo, Japan). The experiment was performed by a professional technician from the Electron Microscopy Center of Henan University of Traditional Chinese Medicine. Fifteen microliters of the prepared exosomes, positive (pure milk) and negative $\left(\mathrm{ddH}_{2} \mathrm{O}\right)$ controls were pipetted onto formvar carbon-coated copper grids, adsorbed for $150 \mathrm{~s}$ and wiped off excess fluids. The absorded exosomes were stained with $3 \%$ uranyl acetate for 3 min, washed with $\mathrm{ddH}_{2} \mathrm{O}$, air-dried for $2 \mathrm{~h}$, and analyzed with a transmission electron microscope at $80-120 \mathrm{kV}$ voltage.

\section{Dynamic light scattering analysis}

A NanoBrook Zetasizer 90Plus PALS (Nano ZS) Instrument (Malvern, UK) was applied for dynamic light scattering. Isolated exosome samples were diluted in PBS. All samples were measured with parameters of using a helium/neon laser $(640 \mathrm{~nm})$ at $220 \mathrm{~V}$ voltage, a temperature of $25^{\circ} \mathrm{C}$ and an angle of $90^{\circ}$. The exosome size data refers to the scattering intensity distribution (z-average) and effective diameter size calculated based on scattering intensity.

\section{Exosome uptake}

\section{PKH26 staining}

Exosomes drived from SGC-7901 cells were labelled with PKH26 kit (PKH26 Red Fluorescent Cell Linker Kit, Sigma, USA). $50 \mu \mathrm{L}$ 
ultracentrifugation exosomes suspended in PBS were added with $100 \mu \mathrm{L}$ Solution C. $0.5 \mu \mathrm{L}$ PKH26 was dissolved in another $100 \mu \mathrm{L}$ solution C. The diluted exosomes were added to the diluted PKH26 rapidly, mixed and incubated for 5 minutes, and $250 \mu \mathrm{L}$ sterile FBS was added to stop staining. The exosomes labelled with PKH26 were isolated using ExoQuick $^{\mathrm{TM}}$ Exosome Isolation Reagent (SBI, USA). $200 \mu \mathrm{g}$ exosomes labelled with PKH26 were added to SGC-7901/ADR cells. After 24 hours, the SGC-7901/ADR cells were fixed by $4 \%$ paraformaldehyde, stained with DAPI, and washed with PBS for three times. Fluorescence signal of PKH26 was observed under a Carl Zeiss LSM710 laser scanning confocal microscope (Oberkochen, Germany).

\section{Transwell coculture}

A stable MGC-803 cell line with exosomes labeled with green fluorescence (MGC-803/pLVX-CD63-AcGFP1) was constructed by our laboratory. MGC-803 cells line or MGC-803-pLVX stable cells line (4 × $10^{5} /$ well) were seeded in the upper chamber of a coculture system with a $0.4 \mu \mathrm{m}$ pore membrane, and the recipient SGC-7901/5-FU $\left(2 \times 10^{5} /\right.$ well $)$ were placed in the lower chamber. All cells were incubated in medium with $10 \%$ exosome-free FBS. After $48 \mathrm{~h}$ of coculture, SGC-7901/5-FU cells were observed under a fluorescence microscope, or collected, washed with PBS, resuspended in $500 \mu 1$ of PBS and the fluorescence signal were detected by FACS Aria II flow cytometry (Becton Dickinson, 
USA).

\section{GW4869 treatment}

GW4869, an inhibitor for the exosome formation and release [21,22], was firstly dissolved in DMSO into a stock solution of $1.5 \mathrm{mM}$, then added with 5\% methanesulfonic acid to increase the solubility in DMSO. SGC7901 cells were treated with GW4869 at a final concentration of 10 $\mu \mathrm{M}$ for $24 \mathrm{~h}$.

\section{miRNA inhibitor and siRNA transfection}

SGC-7901/5-FU cells were transfected with a miR-107 inhibitor (the sequences were 5'-UGAUAGCCCUGUACAAUGCUGCU-3') or miR-107 inhibitor negative control (the sequences were 5'-CAGUACUUUUGUGUAGUACAA-3') at $100 \mathrm{nM}$ with Lipofectamine 2000 (invitrogen, CA, USA). Three siRNAs targeting HMGA2 and negative control were synthesized. The siRNA with the highest gene silencing efficacy was chosen for further use. All the miRNA and siRNA were synthesized by Shanghai Sangon Biotech (Shanghai, China). Co-transfection of $50 \mathrm{nM}$ miR-107 inhibitor and 50 nM HMGA2 siRNA were included.

\section{Luciferase reporter assay}

The targeted binding site of miR-107 to HMGA2 was predicted using TargetScan (http://www.targetscan.org/vert_72/) . HMGA2 wild-type (insert sequence: 5'-gtcTAGTACTTATTAC-ATGCTGCt-3') 
and

mutant-type

(insert

sequence:

5'-gtcTAGTACTTATTACTACGACGt-3') expression vectors were cloned into a Gaussia luciferase (GLuc) reporter vector (pEZX-MT05, Genecopoeia), which contains a reference reporter gene, secreted alkaline phosphatase (SeAP). The HEK 293T cells in 24-well plates were co-transfected with the above wild or mutant reporter vectors with miR-107 mimics or miR-107 mimics NC using transfection reagent Lipofectamine 2000 for $48 \mathrm{~h}$. The activities of GLuc and SeAP were quantified with the secrete-pair dual luminescence assay kit (Genecopoeia).

\section{Western blotting analysis}

Protein extraction of exosomes and cells as well as Western blot analysis were performed according to our previous study [23]. The following antibodies were used: anti-Lamin B1 (\#13435, 1:1000), anti-HSP 70 (\#4872, 1:1000), anti-p-Akt (\#9271, 1:500), anti-Akt (\#9272, 1:1000), anti-P-gp (\#13342, 1:500) (All from Cell Signaling); anti-CD63 (D360973, 1:500) and anti-HMGA2 (D160487, 1:500) (Both from BBI) and anti-GAPDH (CW0100, 1:1000, Beijing Com Win).

\section{Quantitative PCR analysis}

mRNA extraction of cells as well as the relative mRNA level of HMGA2 gene analyzed by quantitative PCR were performed according to our previous study [23]. The primer sequences for HMGA2 were 
5'-GGTGAACTCAAGCCGAAG-3' (antisense) and the primer sequences for the control gene GAPDH were 5'-CGCTGAGTACGTCGTGGAGTC-3' (sense) and 5'-GCTGATGATCTTGAGGCTGTTGTC-3' (antisense). Total micro RNA was extracted from cells and exosomes using miRNA Purification kit (CW0627S, Beijing Com Win), micro RNA (100 300 ng) was reverse transcribed into cDNA by using miRNA cDNA Synthesis kit (CW2141S, Beijing Com Win), and the relative level of miR-107 was determined by qPCR using miRNA qPCR Assay kit (CW2142S, Beijing Com Win). The relative expression of miR-107 was normalized to U6, and the antisense primers of miR-107 and U6 were provided by the above kit. The sense primer sequences for miR-107 were 5'CGCAGCAGCATTGTACAGGGCTATCA-3' and the sense primer $\begin{array}{llll}\text { sequences } & \text { for } & \text { U6 } & \text { were }\end{array}$ 5'-CCGAGAGAAGATTAGCATGGCCCCTG-3'.

\section{Statistics}

All experiments were repeated at least three times except that some WB experiments were repeated twice. A one-way analysis of variance (ANOVA) followed by Dunnett's test was used for multiple comparisons. Values of $P<0.05$ were considered significant, and values of $P<0.01$ were considered extremely significant. All data expressed as mean $\pm \mathrm{SD}$ 
unless otherwise indicated.

\section{Results}

\section{Exosomes derived from SGC-7901 and SGC-7901/5-FU GC cells were isolated and confirmed.}

In order to explore the effects of exosomal contents on the chemotherapeutics sensitivity of SGC-7901 GC cells. We used ultracentrifugation method to extract the exosomes of SGC-7901 and SGC-7901/5-FU cells. It can be observed that the vesicles of sensitive and resistant SGC-7901 cells were goblet-shaped with bilayered membranes, and the diameter ranged from $30 \mathrm{~nm}$ to $180 \mathrm{~nm}$, some confounding proteins in the background also were found under the transmission electron microscope (Fig. 1a). The predominant size and diameter of exosomes were further analyzed by DLS. The results showed that the particle sizes were normally distributed, and the effective particle diameter of the exosomes were around $120 \mathrm{~nm}$ (Fig. 1b). Through western blot analysis, the exosomal marker proteins CD63 and HSP70 were detected in the exosomes, while the nuclear marker protein Lamin B1 was mainly enriched in the whole cell lysates (Fig. 1c). These results indicated that the vesicles extracted from sensitive and resistant SGC-7901 cells exhibited typical exosomal characteristics. 
a

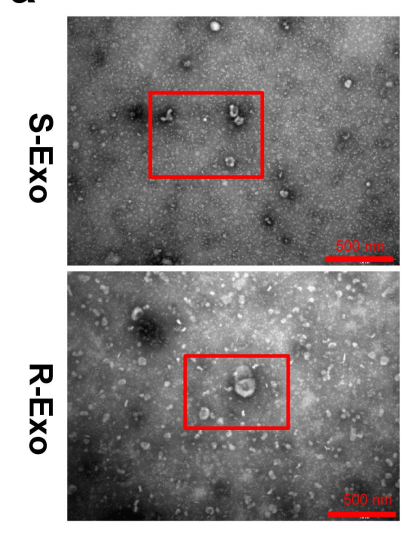

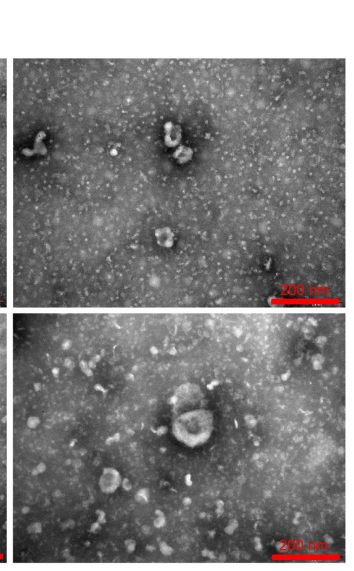

b

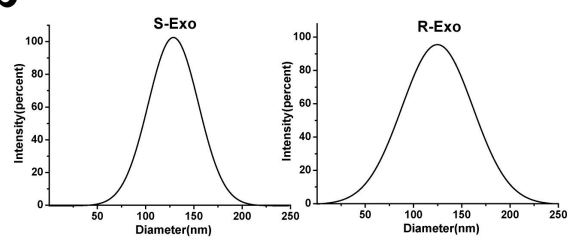

C

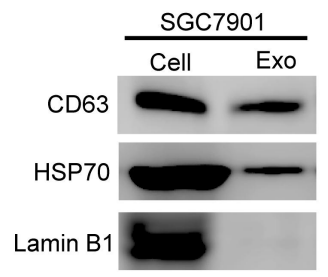

Fig. 1 Characteristics of exosomes drived from SGC-7901 and SGC-7901/5-FU GC cells. a The transmission electron micrograph showed round-shaped vesicles with bilayered membranes ranging from $30 \mathrm{~nm}$ to $180 \mathrm{~nm}$ in diameter released by SGC-7901 (S-Exo) and SGC-7901/5-FU (R-Exo) cells. Scale bar $=500 \mathrm{~nm}$ and 200 $\mathrm{nm}$, respectively. b Dynamic light scattering analysis (DLS) indicated that the dominant size of S- and R-Exo was about $120 \mathrm{~nm}$. c The positive markers of exosomes, CD63 and HSP70, were detected in S- and R-Exo by Western blot.

SGC-7901/5-FU cells were resistant to chemotherapy drugs 5-fluorouracil and cisplatin

We first determined the drug sensitivity of SGC-7901, MGC-803 sensitive cells and SGC-7901/5-FU resistant cells to the chemotherapy drugs 5-fluorouracil (5-FU) and cisplatin (DDP). As shown in Fig. 2, the SGC-7901/5-FU cell lines were resistant to 5-FU and also cross-resistant to DDP compared with SGC-7901 and MGC-803 sensitive cells. the $\mathrm{IC}_{50}$ values of 5-FU and DDP in the SGC-7901/5-FU were about ten times more than that in the SGC-7901 and MGC-803 cells. 

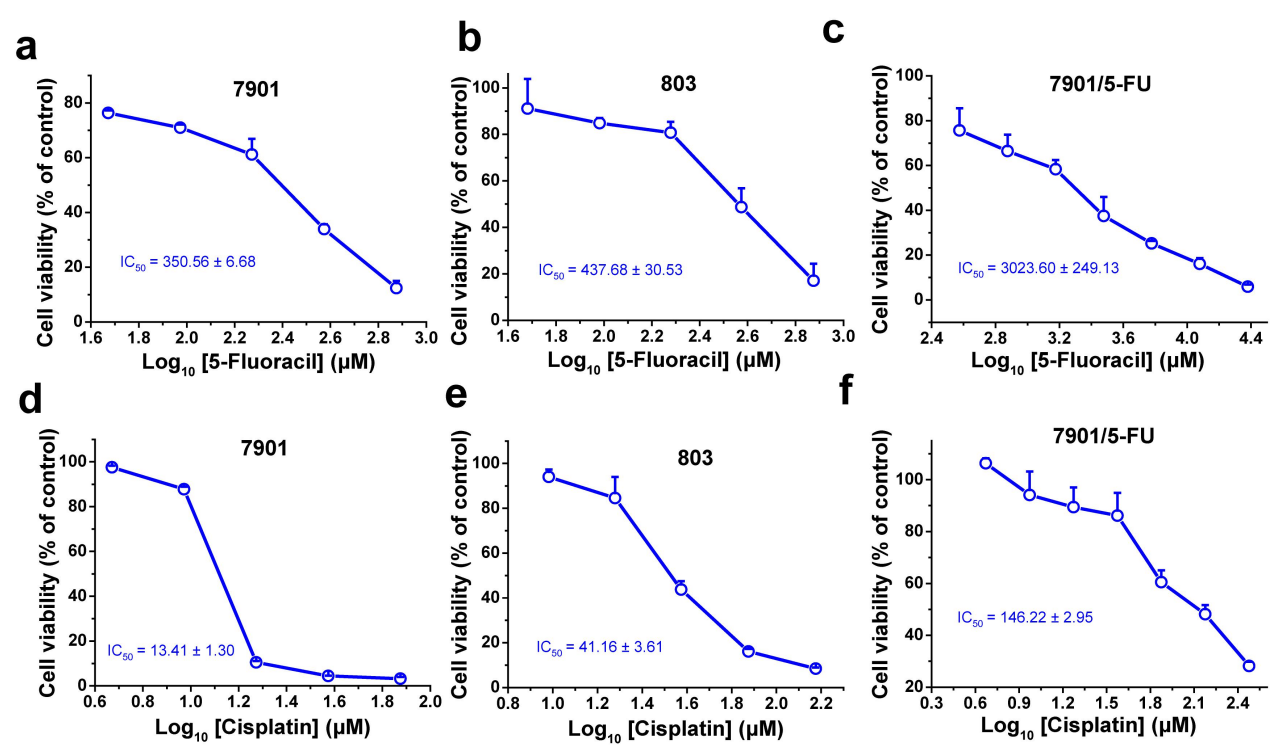

Fig. 2 The sensitivity of GC cells to the chemotherapy drugs 5-FU and DDP. The cell viability of SGC-7901 (a and d), MGC-803 (b and e) sensitive cell strains and SGC-7901/5-FU (c and f) resistant cell strains after treated with 5-FU for $48 \mathrm{~h}(\mathbf{a}, \mathbf{b}, \mathbf{c})$ and DDP (d, e, f) for $24 \mathrm{~h}$, respectively. Cell viability was determined by MTT assay. Cells treated with vehicle serve as a blank control. All experiments were conducted in quintuplicates and data were expressed as the mean $\pm \operatorname{SD}(n=5)$

The exosomes isolated from SGC-7901 and MGC-803 cells increased the sensitivity of SGC-7901/5-FU cells to 5-FU and DDP

In order to explore whether exosomes could regulate the chemotherapy drug sensitivity of GC resistant cells, we extracted the exosomes of SGC-7901 and MGC-803 sensitive cells, and treated with SGC-7901/5-FU drug-resistant cells at a certain dose. The results showed that exosomes extracted from MGC-803 and SGC-7901 increased the sensitivity of SGC-7901/5-FU cells to 5-FU and DDP. In the presence of MGC-803- and SGC-7901-secreted exosomes, the $\mathrm{IC}_{50}$ values $(\mu \mathrm{M})$ of 5-FU in the SGC-7901/5-FU resistant cells decreased from 3023.60 to 
1718.14 and 1020.82 , respectively, and the $\mathrm{IC}_{50}$ values $(\mu \mathrm{M})$ of DDP in the SGC-7901/5-FU resistant cells decreased from 146.22 to 116.46 and 82.85, respectively. What's more, the effects of exosomes from SGC-7901 cells were much stronger than that from MGC-803 cells, the $\mathrm{IC}_{50}$ values of 5-FU and DDP of SGC-7901/5-FU cells treated with SGC-7901 exosomes were about 3 and 2 times lower than that without exosomes treatment, respectively (Fig. 3). Altogether, the exosomes isolated from SGC-7901 and MGC-803 cells reversed the resistance of SGC-7901/5-FU to the chemotherapeutic agents.

a

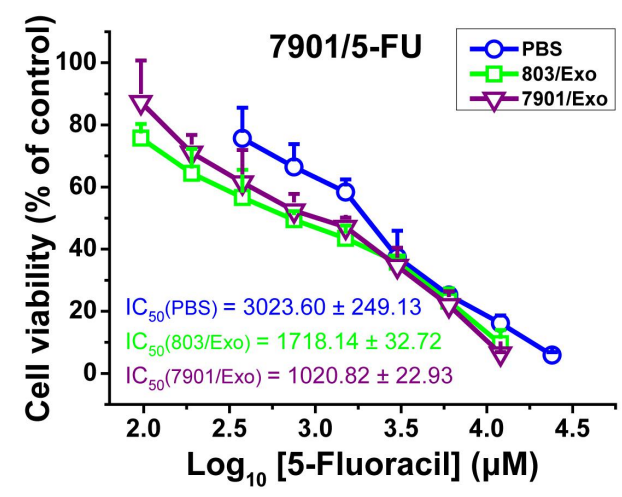

b

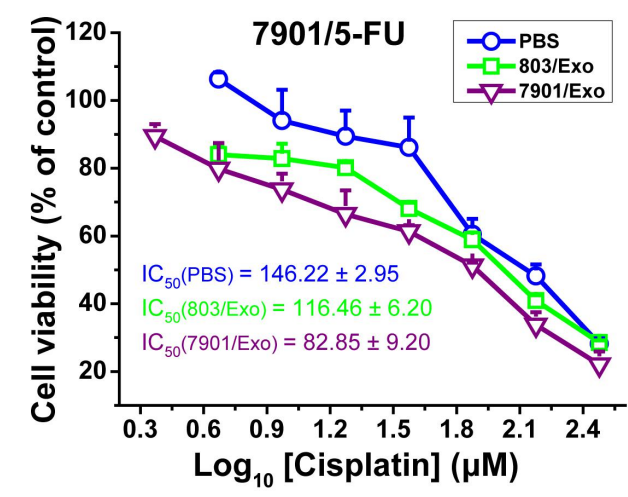

Fig. 3 The exosomes isolated from sensitive GC cells increased drug sensitivity of drug-resistant GC cells. The cell viability of SGC-7901/5-FU cells after treated with 5-FU (a) or DDP (b) with or without the exosomes isolated from SGC-7901 or MGC-803 cells for 48 or $24 \mathrm{~h}$, respectively. Cell viability was determined by MTT assay. Cells treated with vehicle serve as a blank control. Abbreviations: Exo, exosomes. All experiments were conducted in quintuplicates and data were expressed as the mean $\pm \operatorname{SD}(n=5)$.

The SGC-7901/5-FU recipient cells absorbed exosomes from sensitive 


\section{GC cells}

In order to visualize the exosomes were absorbed, we labeled SGC-7901-secreted exosomes with PKH26, which is a red fluorescent tracer. After incubation of labeled exosomes with SGC-7901/5-FU cells, we observed strong red fluorescence in the cytoplasm of recipient cells and the labeled exosomes gathered around the nucleus in dots or clots under a confocal fluorescence microscope (Fig. 4a), which showed that SGC-7901 secreted exosomes were successfully taken up by SGC-7901/5-FU recipient cells. To visualize exosome transfer, MGC-803 cells or MGC-803-pLVX stable cells were replated in the upper chamber of a coculture system with $0.4 \mu \mathrm{m}$ pores, which inhibit directly contact with the cells and allow the transmission of exosomes but not larger particles. After $48 \mathrm{~h}$ of coculture, we also observed green fluorescence appeared in the cytoplasm of SGC-7901/5-FU cells, although the numbers of green vesicles is relatively weak (Fig. 4b). Also, compared with the group of MGC-803 normal cells, about $16 \%$ green fluorescence signal were detected by FACS analysis in MGC-803-pLVX stable cells group (Fig. 4c), which demostrated that the exosomes labeled with green fluorescence and exosomal contents might be directly transferred from MGC-803 donor cells to SGC-7901/5-FU recipient cells. All together, these results indicted that exosomes could shuttle from the sensitive GC cells to the SGC-7901/5-FU resistant GC cells, since exosomes could be 
taken up by SGC-7901/5-FU cells, we deduced that the contents of exosomes would also be uptaken by resistant cells.
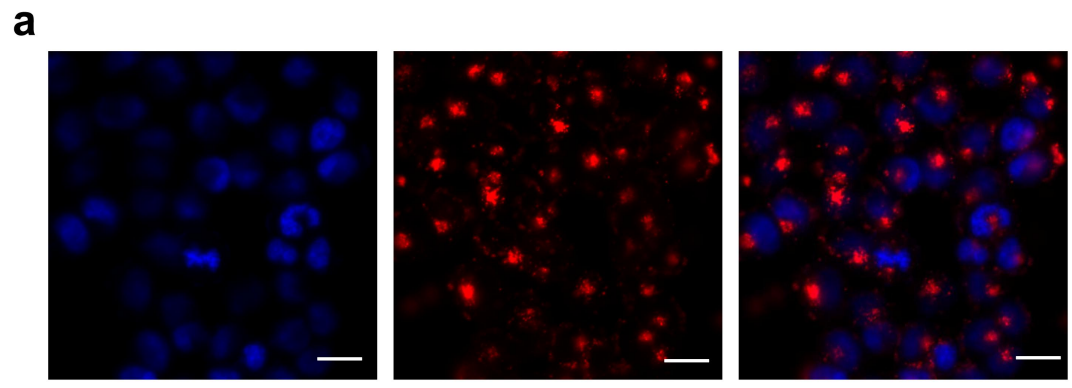

b
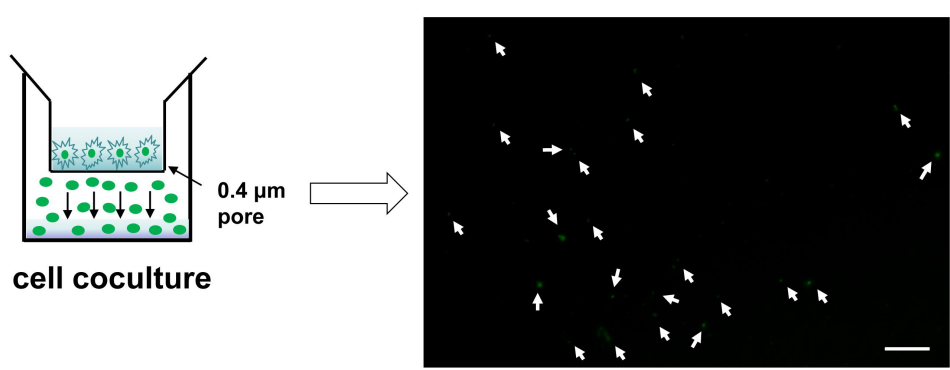

C
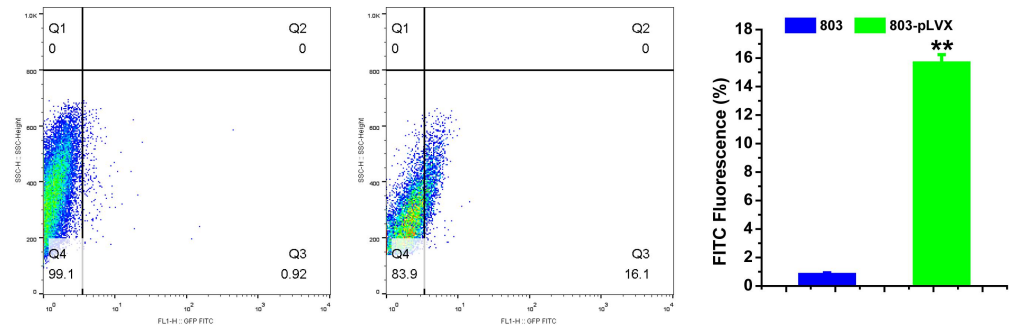

Fig. 4 Exosomes derived from sensitive GC cells were taken up by SGC-7901/5-FU cells. a Confocal microscopy showed exosome internalization by SGC-7901/5-FU recipient cells after co-incubation with PKH26-labeled SGC-7901 exosomes. Red: exosomes stained with PKH26, blue: DAPI. Scale Bars $=20 \mu \mathrm{m}$. b The MGC-803-pLVX stable cells were placed in the upper chamber and coincubated with SGC-7901/5-FU cells seeded in the lower chamber in a coculture system with a 0.4 $\mu \mathrm{m}$ pore membrane. Green fluorescence were observed in the SGC-7901/5-FU recipient cells under the fluorescence microscope. Scale Bars $=35 \mu \mathrm{m}$. c The percentage of green fluorescence signals in SGC-7901/5-FU resistant GC cells were determined by flow cytometry. Data were expressed as the mean \pm SD $(n=3)$. Statistical significances were determined using one-way ANOVA followed by Dunnett's test. ${ }^{* *} P<0.01$, compared with the group of MGC-803 cells. 
SGC-7901-secreted exosomal miR-107 reversed drug resistance of SGC-7901/5-FU cells by targeting HMGA2

We also tested the expression levels of miR-107 and HMGA2 in the SGC-7901, MGC-803 sensitive and SGC-7901/5-FU resistant cells and exosomes, and found that the expression levels of miR-107 in MGC-803 cells and exosomes were lower than that of SGC-7901 cells and exosomes, moreover, the miR-107 levels in SGC-7901/5-FU resistant cells and exosomes were significantly lower than that of SGC-7901 and MGC-803 cells and exosomes (Fig. 5a and c). Simultaneously, the expression level of HMGA2 in MGC-803 was higher than that of SGC-7901 cells, and in SGC-7901/5-FU resistant cells, the HMGA2 level was significantly higher than that of SGC-7901 and MGC-803 cells (Fig. 5b). These results indicated that the expression of miR-107 in drug-resistant cells and exosomes were significantly different compared to sensitive cells and exosomes, and the target molecules of miR-107 may be HMGA2. Thus, we reasoned that miR-107 from sensitive cells exosome may reverse chemotherapy drugs resistance of SGC-7901/5-FU cells via exosome transfer. 

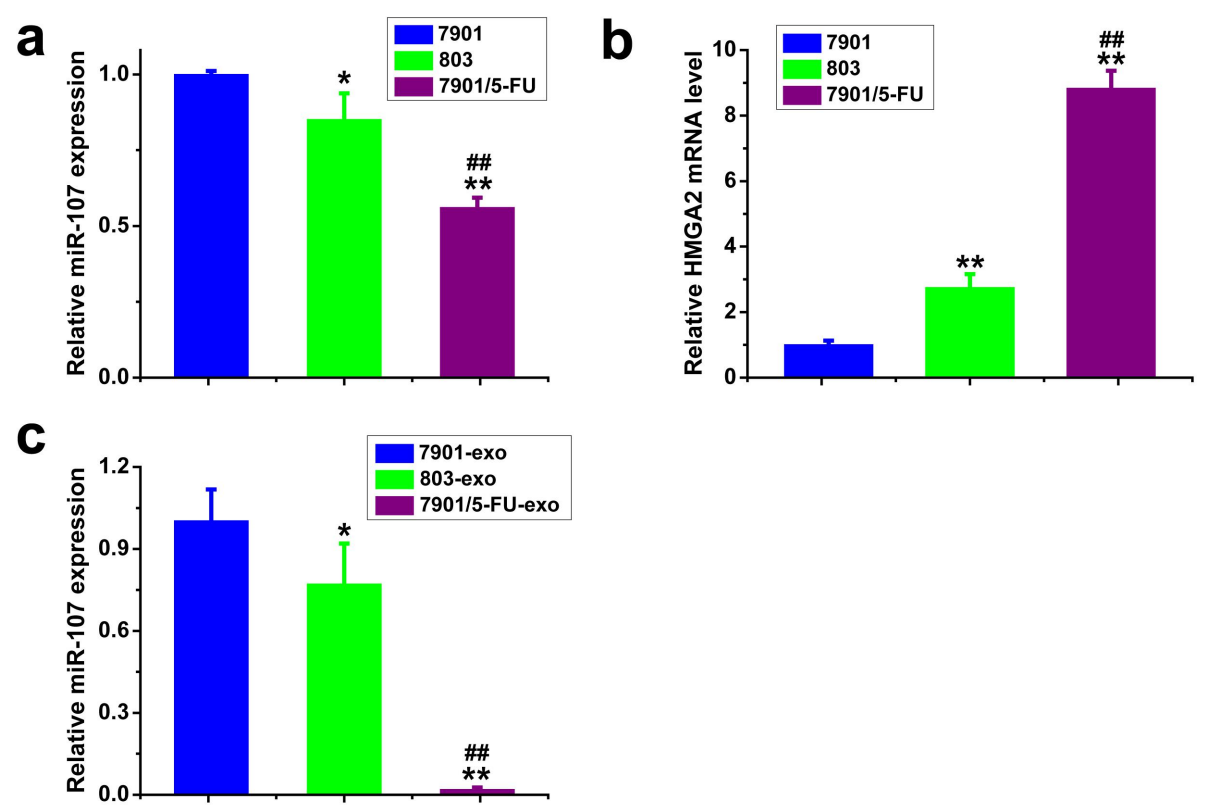

Fig. 5 The expression levels of miR-107 and HMGA2 in SGC-7901, MGC-803 and SGC-7901/5-FU cells and exosomes were detected by qPCR. the expression levels of miR-107 (a) and HMGA2 (b) in SGC-7901, MGC-803 sensitive and SGC-7901/5-FU resistant cells; the expression levels of miR-107 (c) in SGC-7901, MGC-803 sensitive and SGC-7901/5-FU resistant exosomes. mRNA and miRNA levels were determined by qPCR using GAPDH and U6 as the internal control, respectively. Data were expressed as the mean $\pm \mathrm{SD}(\mathrm{n}=3)$. Statistical significances were determined using one-way ANOVA followed by Dunnett's test. ${ }^{*} P<0.05$, ${ }^{* *} P<0.01$, compared with SGC-7901 cells/exosomes; ${ }^{\#} P<0.01$, compared with MGC-803 cells/exosomes.

\section{HMGA2 was the target gene of miR-107}

According to the Targetscan software analysis, HMGA2 3'-UTR had a pseudo binding site with miR-107 (Fig. 6a). To verify this prediction, a luciferase reporter assay was performed. The results showed that the overexpression of miR-107 reduced the luciferase activity in $293 \mathrm{~T}$ cells cotransfected with the pEZX-MT05-MT reporter plasmid containing 
HMGA2 3'-UTR wild type, however, there has no significant changes of the luciferase activity were observed in $293 \mathrm{~T}$ cells cotransfected with the pEZX-MT05-MUT reporter plasmid containing HMGA2 3'-UTR mutant type (Fig. 6b). What's more, we found that the protein expression level and mRNA level of HMGA2 were significantly up-regulated treated with miR-107 inhibitor (Fig. 9c,f and Fig. 10a). All together, these results demostrated that HMGA2 was the target molecular of miR-107.

a

HMGA2-WT 5'- gtcTAGTACTTATTAC-ATGCTGCt -3'

hsa-miR-107 3'- acuAUCGGGACAUGUUACGACGa -5'

HMGA2-MUT 5'- gtcTAGTACTTATTAC-TACGACGt -3'

b

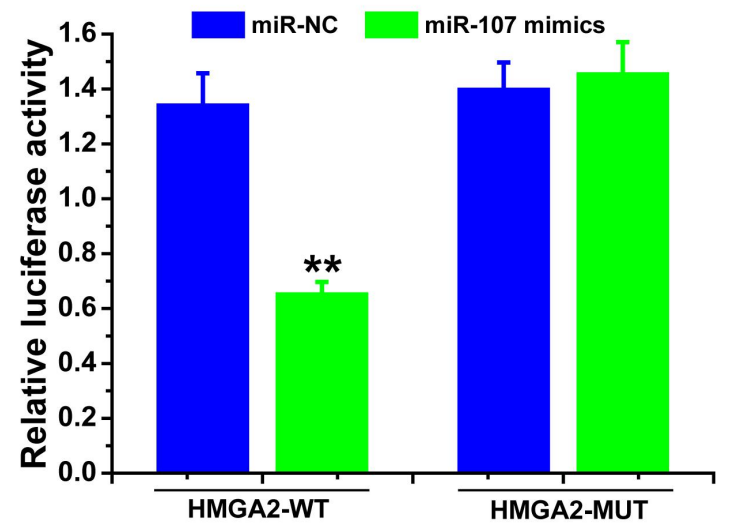

Fig. 6 Downstream target molecular of miR-107 was HMGA2. a Predicted binding sites of miR-107 in HMGA2 3'-UTR. b Plasmid vectors of human HMGA2 3'-UTR or its mutation were transfected into $293 \mathrm{~T}$ cells together with miR-107 mimics or NC. Data were expressed as fold change of the luciferase activity over the control from the $\mathrm{NC}$ group (mean $\pm \mathrm{SD}, \mathrm{n}=3$ ). Statistical significances were determined using one-way ANOVA followed by Dunnett's test. ${ }^{* *} P<0.01$, compared with respective controls. 


\section{The drug resistance of $\mathrm{SGC-7901/5-FU}$ cells was reversed via exosomes transfer of SGC-7901 cells}

In order to verified that the improved drug sensitivity of SGC-7901/5-FU cells was indeed mediated by sensitive cells-secreted exosomes, we treated SGC-7901 cells with the GW4869, which inhibits the synthesis and secretion of exosomes, and treated SGC-7901/5-FU cells combined with exosomes and 5-FU or DDP. We found that the SGC-7901-secreted exosomes, which treated with GW4869, could no longer increased the drug sensitivity of SGC-7901/5-FU cells to 5-FU and DDP compared with SGC-7901-secreted exosomes, which treated with DMSO (Fig. 7). These results showed that the drug resistance of SGC-7901/5-FU cells was reversed by exosomes transfer of SGC-7901 cells.

a

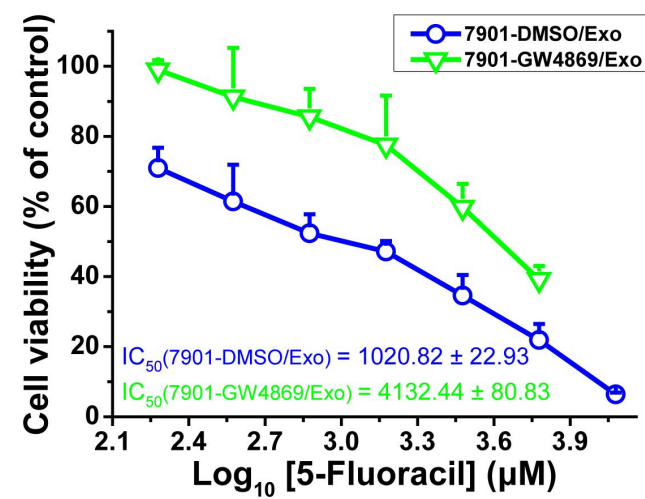

b

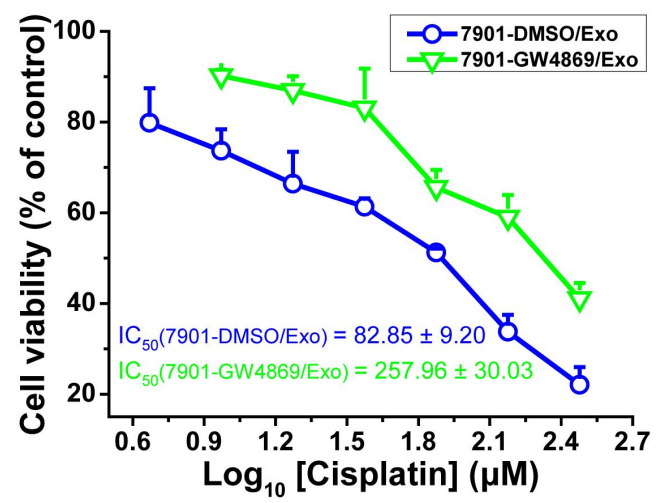

Fig. 7 Exosomes transfer increased drug sensitivity of SGC-7901/5-FU cells. The cell viability of SGC-7901/5-FU cells after treated with 5-FU (a) or DDP (b) combined with exosomes extracted from SGC-7901 cells (with or without the exosome inhibitor GW4869 treatment) for 48 or $24 \mathrm{~h}$, respectively. Cell viability was determined by 
MTT assay. Cells treated with vehicle serve as a blank control. Abbreviations: Exo, exosomes. All experiments were conducted in quintuplicates and data were expressed as the mean $\pm \operatorname{SD}(n=5)$.

Exosomal miR-107 secreted by SGC-7901 reversed drug resistance of SGC-7901/5-FU cells through targeting HMGA2.

In order to evaluated whether exosomal miR-107 increased drug sensitivity in SGC7901/5-FU cells by targeting HMGA2, we transfected SGC-7901/5-FU cells with a miRNA-107 inhibitor (107 i), the co-transfection of the miRNA-107 inhibitor and siRNA specific for HMGA2 (107i + siHMGA2) and negative control of miRNA-107 inhibitor/siHMGA2 (NC). As showen in Fig. 8, SGC-7901 exosomes dramatically increased the drug sensitivity of SGC-7901/5-FU (NC) cells to the 5-FU and DDP, whereas no significant difference was seen in miR-107 silenced SGC-7901/5-FU (107 i) cells. What's more, the SGC-7901 exosomes also reversed the resistance of SGC-7901/5-FU $(107 i+$ siHMGA2) cells to 5-FU and DDP. Taken together, these results suggested that the exosomes secreted by sensitive cells no longer increased the sensitivity of miR-107 konckdown SGC7901/5-FU cells to chemotherapy drugs 5-FU and DDP, and reversed drug resistance can be achieved by exosomal transfer of miR-107 possibly through inhibiting HMGA2 expression in SGC-7901/5-FU cells. 
a

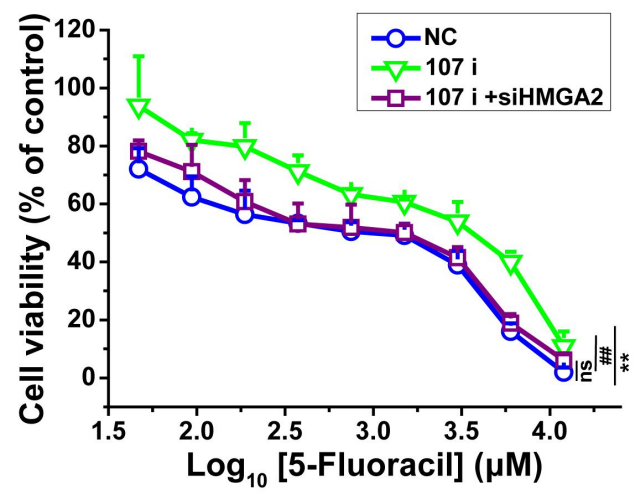

b

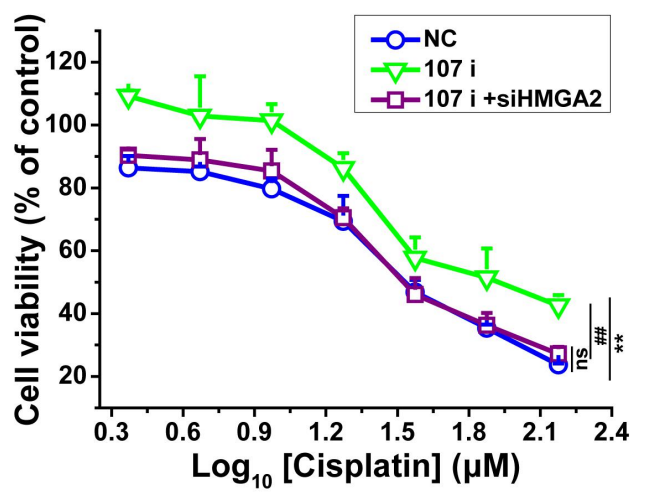

Fig. 8 SGC-7901-secreted exosomal miR-107 reversed drug resistance of SGC-7901/5-FU cells by inhibiting HMGA2. The SGC-7901/5-FU cells were transfected with miRNA-107 inhibitor, co-transfection with miRNA-107 inhibitor and siRNA traget for HMGA2 and miRNA-107 inhibitor/siHMGA2 negative control for $24 \mathrm{~h}$, and the cell viability of SGC-7901/5-FU cells after treated with different concentrations of 5-FU (a) or DDP (b) combined with exosomes extracted from SGC-7901 cells for 48 or $24 \mathrm{~h}$, respectively. Cell viability was determined by MTT assay. Cells treated with vehicle serve as a blank control. Abbreviations: Exo, exosomes. All experiments were conducted in quintuplicates and data were expressed as the mean $\pm \mathrm{SD}(\mathrm{n}=5)$. Statistical significances were determined using one-way ANOVA followed by Dunnett's test. ${ }^{* *} P<0.01$, compared with negative control transfection group; ${ }^{\#} P<0.01$, compared with miRNA-107 inhibitor/siHMGA2 co-transfection group; ns, no significance $(P>0.05)$, comparison between negative control transfection group and miRNA-107 inhibitor/siHMGA2 co-transfection group.

\section{Exosomal miR-107 reversed drug resistance of SGC-7901/5-FU recipient cells through HMGA2/mTOR/P-gp pathway}

We then sought to reveal the underlying molecular mechanism of how exosomal miR-107/HMGA2 axis reversed drug resistance of SGC-7901/5-FU cells. In our experiments, we found that HMGA2 and 
P-gp were significantly higher expression and mTOR was over-activated in SGC-7901/5-FU cells compared with the SGC-7901 and MGC-803 cells (Fig. 9a and d). As shown in Fig. 9b,c,e,f and Fig. 10, the protein expression levels of HMGA2, p-mTOR (Ser 2448), P-gp and the mRNA level of HMGA2 in SGC-7901/5-FU cells were significantly down-regulated by SGC7901-secreted exosomes treatment and transfected with NC or co-transfected with $107 i+$ siHMGA2. Conversely, inhibition of exosome secretion or miR-107 knockdown in SGC-7901/5-FU cells increased the protein expression levels of HMGA2 p-mTOR, P-gp and the mRNA level of HMGA2. All in all, these results demonstrated that the increased sensitivity of cells to chemotherapeutic drugs by exosomal miR-107 was mediated by inhibiting the expression of HMGA2 and the activity of HMGA2/mTOR/P-gp axis.

a

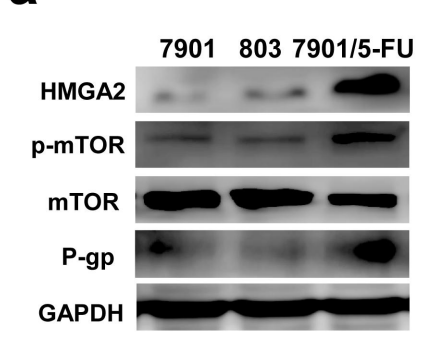

d

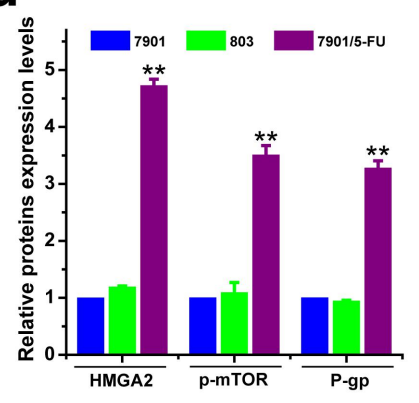

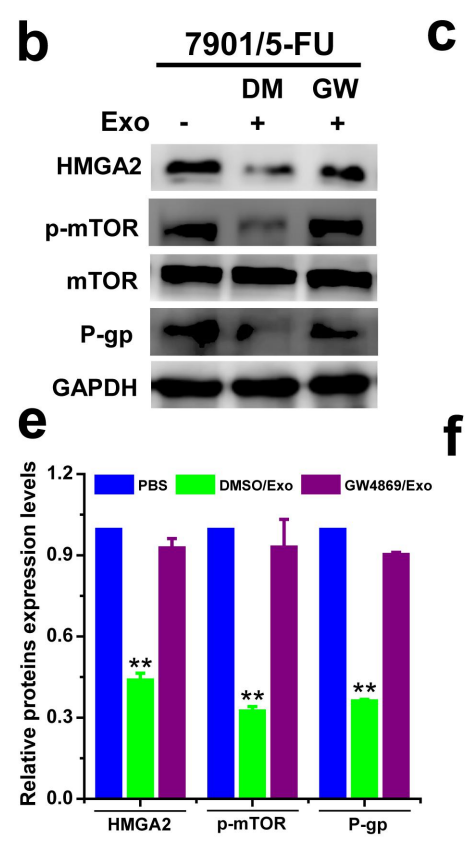


Fig. 9 Exosomal miR-107 reversed drug resistance of SGC-7901/5-FU cells by downregulating HMGA2/mTOR/P-gp pathway. The protein expression levels of HMGA2, p-mTOR/mTOR, P-gp (a-c) and corresponding quantitative analysis (d-f) of SCG7901, MGC-803 and SCG7901/5-FU cells treated with or without exosomal inhibitor GW4869 and transfected with miR-107 inhibitor, co-transfected with miRNA-107 inhibitor/siHMGA2 or negative control were determined. The protein expression levels were detected by western blotting analysis using GAPDH as internal control. Cells treated with vehicle, or transfected with control miRNA or siRNA serve as control. Abbreviations: Exo, exosome; DM, DMSO; GW, GW4869; NC, negative control. Data in a-c are the representative of two independent experiments. Statistical significances in d-f were determined using one-way ANOVA followed by Dunnett's test. ${ }^{* *} P<0.01$, compared with the respective controls or sensitive cells.

a

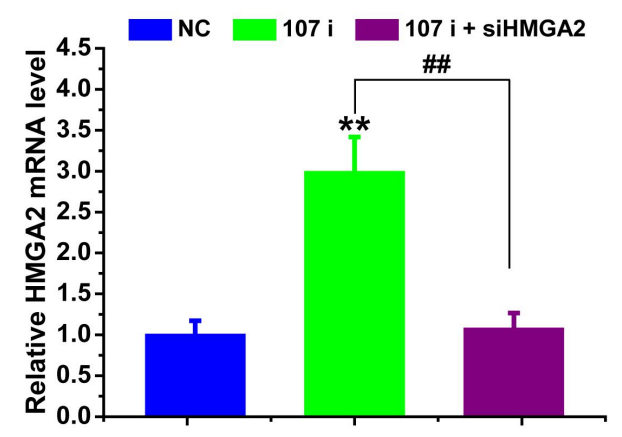

b

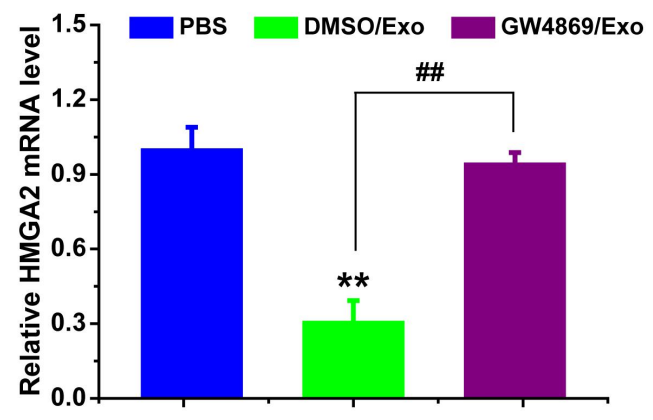

Fig. 10 Exosomal miR-107 increased drug sensitivity of SCG-7901/5-FU cells by regulating the mRNA level of HMGA2. mRNA level of HMGA2 of SCG-7901/5-FU cells transfected with miR-107 inhibitor, co-transfected with miRNA-107 inhibitor/siHMGA2 or negative control (a) and treated with or without exosomal inhibitor GW4869 (b) were detected. mRNA levels were determined by qPCR using GAPDH as the internal control. Cells treated with vehicle, or transfected with control miRNA or siRNA serve as control. Abbreviations: Exo, exosome; DM, DMSO; GW, GW4869; NC, negative control. Data were expressed as the mean $\pm \mathrm{SD}(\mathrm{n}=3)$. Statistical significances were determined using one-way ANOVA followed by Dunnett's test. ${ }^{* *} P<0.01$, compared with the respective controls; ${ }^{\#} P<0.01$, 
comparison between the two columns.

\section{Discussion}

In recent years, the regulation of exosomal miRNAs on cancer cells was a research hotspot, and chemotherapy resistance seriously affects the treatment of GC. In this study, we showed that exosomes drived from sensitive GC cells could increased the sensitivity of resistant GC cells to chemotherapeutic drugs. The reversal effects were mediated by exosomal miR-107 and exosomal miRNA-107 reversed chemotherapy resistance through targeting HMGA2 and regulating the activity of HMGA2/mTOR/P-gp pathway (Fig. 11).

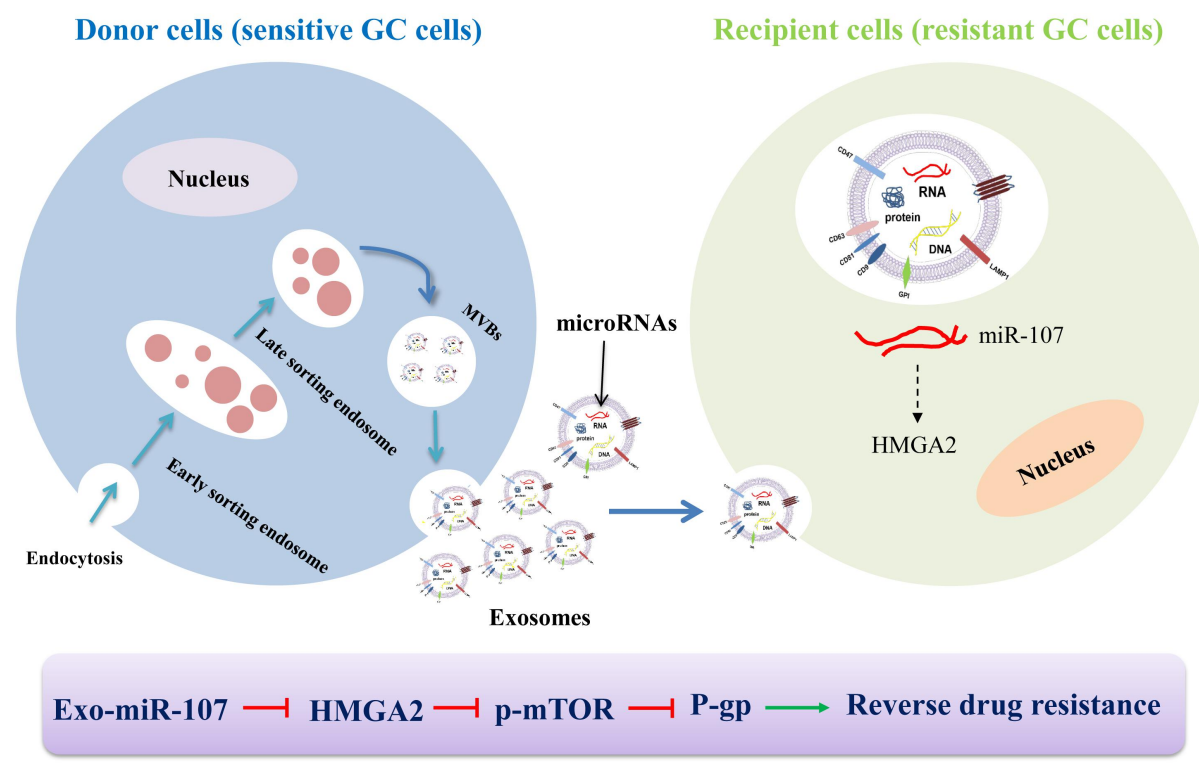

Fig. 11 The possible mechanism of exosomal miR-107 reversed chemotherapeutic drug resistance of SGC-7901/5-FU cells. exosomal miR-107 transmitted from sensitive GC cells to recipient resistant GC cells, and improved drug sensitivity of SGC-7901/5-FU cells through inhibiting HMGA2/mTOR/P-gp signal. 
Exosomes are a subgroup of extracellular vesicles, which as a carrier of cell contents (proteins, nucleic acid, lipids), it was an important way of intercellular communication [24], In the past few years, exosomes played more and more important role in mediating communication between cells, and its contents also play a certain role in mediating cancer cells resistance [25]. There are four manners to achieve the connection between exosomes and cells, which including 1, exosomes recognize the surface receptors by ligand-receptor binding. 2, exosomes directly fuse with target cells to achieve receptor transfer. 3, exosomes fuse with target cells and release content proteins. 4, exosomes transfer genetic information (mRNA, non-coding RNA, DNA) to target cells [26]. The interaction of exosomes and targets cells was a crucial step to induce biological effect, thus we also used a variety of methods, such as PKH26 staining, transwell and flow cytometry, to prove sensitive GC cells secreted exosomes were uptaked by receptor-resistant GC cells. And the inhibitor GW4689, which inhibits the synthesis and release of exosomes, was used to prove that the exsomes from sensitive GC cells could reverse drug resistance of SGC-7901/5-FU cells.

There have been many reports that the regulatory role of exosomal miRNA on chemotherapy resistance of cancer cells. Such as exosomal microRNA-32-5p induces multidrug resistance in hepatocellular 
carcinoma [27], macrophages derived exosomal miR-223 induced a chemoresistant phenotype of epithelial ovarian cancer cells through exosomal miR-223/PTEN-PI3K/AKT signaling pathway [28]. In GC cells, the MGC-803 sensitive cells became resistant to paclitaxel mediated by exosomal miRNA-155-5p through inhibiting the expressions of GATA3 and TP53INP1 [29], MGC803/DDP-derived exosomes enhance DDP resistance of MGC803 recipient cells via exosomal delivery of miR-500a-3p [30]. Although a variety of exosomal miRNAs have been reported to regulate chemotherapeutics sensitivity of cancer cells, the effect of exosomal miRNA-107 on the drug resistance of GC cells has not been reported. In our study, we first found that exosomal miR-107 from sensitive GC cells could increase the sensitivity of resistant GC cells to chemotherapy drugs 5-FU and DDP, thus, exosomal miR-107 might provide a new target for improving the drug sensitivity of GC patients.

Some reports demostrated that HMGA2 also had a certain effect on the chemotherapeutics sensitivity of cancer cells. HMGA2 regulated the progression and the sensitivity of acute myeloid leukemia to daunorubicin by activating the $\mathrm{Wnt} / \beta$-catenin signaling pathway [31], miR-26a could regulate the resistance of human non-small cell lung cancer to cisplatin by regulating the expression of HMGA2 through the E2F1-Akt pathway [32], In GC cells, HMGA2 might be a potential target molecular of 
miR-33b-5p, up-regulation of miR-33b-5p reduced the expression of HMGA2, inhibited the growth of GC cells, and improved the sensitivity of GC cells to chemotherapy drugs [33]. Some literatures suggested that HMGA2 might be the target of miRNA-107, miRNA-107 could inhibit the proliferation of liver cancer cells by targeting HMGA2 mRNA 3'-UTR [34], LncRNA LINC00152 promoted the progression of glioblastoma by targeting miR-107 and regulating the expression of HMGA2 [35]. We deduced that miR-107 might regulate the drug sensitivity of GC cells by targeting HMGA2, also in our study, we verified that HMGA2 was the target molecular of exosomal miR-107 using luciferase reporter assay, western blotting and qPCR assay. And exosomal miR-107 improved the sensitivity of resistant GC cells to chemotherapy drugs by targeting HMGA2.

Some studies indicated that HMGA2 could regulate the downstream mTOR signal [36], Tan L et al. reported that aberrant expression of HMGA2 induced acute myeloid leukemia cell proliferation through the PI3K/Akt/mTOR signaling pathway [37], miR-590 suppressed proliferation and induced apoptosis of pancreatic cancer by targeting HMGA2 and inhibiting the phosphorylation mTOR [38]. As we have known, a major mechanism of resistance in cancer cells is the overexpression of $\mathrm{P}$-gp, also known as multidrug resistance protein 1 (MDR1) or ABCB1, which belong to ATP-binding cassette (ABC) 
transporters and could efflux the chemotherapeutic agents out of cells [39]. Some studies showed that mTOR signal could regulate the expression of P-gp and affect the drug resistance of cancer cells [40-42]. In this study, we also found that the expression of P-gp could be regulated by mTOR signal, and exosomal miR-107 regulated the expression of P-gp mediated by HMGA2 and the activity of mTOR signal.

\section{Conclusion}

In summary, our study reveals that exosome-transmitted miR-107 increased the sensitivity of resistant GC cells to the chemotherapeutic drugs. Mechanistically, the expression of target molecular HMGA2 and the activity of $\mathrm{HMGA} 2 / \mathrm{mTOR} / \mathrm{P}-\mathrm{gp}$ signal were downregulated by horizontal transfer of exosomal miR-107. Therefore, we propose that exosomal miR-107 might be used as a potential diagnostic biomarker and therapeutic target for gastric cancers.

\section{Reference}

1. Arbyn M, Weiderpass E, Bruni L, de Sanjosé S, Saraiya M, Ferlay J, Bray F. Estimates of incidence and mortality of cervical cancer in 2018: a worldwide analysis. Lancet Glob Health. 2020;8(2):e191-e203. Https://doi.org/10.1016/S2214-109X(19)30482-6

2. Smyth EC, Nilsson M, Grabsch HI, van Grieken NC, Lordick F. Gastric cancer. Lancet. 2020;396(10251):635-648.

Https://doi.org/ $10.1016 / \mathrm{S} 0140-6736(20) 31288-5$.

3. Liu X, Lu Y, Xu YC, Hou SZ, Huang JL, Wang B, et al. Exosomal transfer of miR-501 confers doxorubicin resistance and tumorigenesis via targeting of BLID in gastric cancer. Cancer Lett. 2019;459:122-134. Https://doi.org/ 10.1016/j.canlet.2019.05.035. 
4. He ZY, Li Z, Zhang X, Yin K, Wang WZ, Xu ZP, et al. MiR-422a regulates cellular metabolism and malignancy by targeting pyruvate dehydrogenase kinase 2 in gastric cancer. Cell Death Dis. 2018;9:505. Https://doi.org/10.1038/s41419-018-0564-3.

5. Pastan I, Gottesman MM. Multidrug resistance. Annu Rev Med. 1991;42: 277-286. Https://doi.org/10.1146/annurev.me.42.020191.001425.

6. Mowla M, Hashemi A. Functional roles of exosomal miRNAs in multi-drug resistance in cancer chemotherapeutics. Exp Mol Pathol. 2021;118:104592. Https://doi.org/10.1016/j.yexmp.2020.104592.

7. Santos P, Almeida F. Role of exosomal miRNAs and the tumor microenvironment in drug resistance. Cells. 2020;9(6):1450. Https://doi.org/10.3390/cells9061450.

8. Zhang Y, Bi JY, Huang JY, Tang YN, Du SY, Li PY, et al. Exosome: a review of its classification, isolation techniques, storage, diagnostic and targeted therapy applications. Int J Nanomedicine. 2020;15:6917-6934. Https://doi.org/10.2147/IJN.S264498.

9. Mashouri L, Yousefi H, Aref AR, Ahadi AM, Molaei F, Alahari SK. Exosomes: composition, biogenesis, and mechanisms in cancer metastasis and drug resistance. $\quad$ Mol Cancer. $2019 ; 18(1): 75$. Https://doi.org/10.1186/s12943-019-0991-5.

10. Liu T, Zhang X, Du LT, Wang YS, Liu XM, Tian H, et al. Exosome-transmitted miR-128-3p increase chemosensitivity of oxaliplatin-resistant colorectal cancer. Mol Cancer. 2019;18(1):43. Https://doi.org/10.1186/s12943-019-0981-7.

11. Ma YZ, Yuwen DL, Chen JW, Zheng BF, Gao J, Fan MM, et al. Exosomal transfer of cisplatin-induced miR-425-3p confers cisplatin resistance in NSCLC through activating autophagy. Int J Nanomedicine. 2019;14:8121-8132. Https://doi.org/10.2147/IJN.S221383

12. Liang Y, Zhu DX, Hou LD, Wang Y, Huang X, Zhou C, et al. MiR-107 confers chemoresistance to colorectal cancer by targeting calcium-binding protein $39 . \mathrm{Br}$ J Cancer. 2020;122(5):705-714. Https://doi.org/10.1038/s41416-019-0703-3.

13. Jiao YN, Kong L, Yao YJ, Li SH, Tao ZY, Yan YH, Yang JX. Osthole decreases beta amyloid levels through up-regulation of miR-107 in Alzheimer's disease. Neuropharmacology. 2016;108:332-344. Https://doi.org/10.1016/j.neuropharm.2016.04.046.

14. Lin SS, Yuan LJ, Niu CC, Tu YK, Yang CY, Ueng SWN. Hyperbaric oxygen inhibits the HMGB1/RAGE signaling pathway by upregulating Mir-107 expression in human osteoarthritic chondrocytes. Osteoarthritis Cartilage. 2019;27(9):1372-1381. Https://doi.org/10.1016/j.joca.2019.05.011.

15. Lu CJ, Xie ZB, Peng QZ. miRNA-107 enhances chemosensitivity to paclitaxel by targeting antiapoptotic factor Bcl-w in non small cell lung cancer. Am J Cancer Res. 2017;7:1863-1873. 
16. Wang GS, Ma CP, Shi XJ, Guo WC, Niu JX. miR-107 enhances the sensitivity of breast cancer cells to paclitaxel. Open Med (Wars). 2019;14:456-466. Https://doi.org/10.1515/med-2019-0049.

17. Inoue T, Iinuma H, Ogawa E, Inaba T, Fukushima R. Clinicopathological and prognostic significance of microRNA-107 and its relationship to DICER1 mRNA expression in gastric cancer. Oncol Rep. 2012;27(6):1759-64. Https://doi.org/10.3892/or.2012.1709.

18. Vignali R, Marracci S. HMGA Genes and Proteins in Development and Evolution. Int J Mol Sci. 2020;21(2):654. Https://doi.org/10.3390/ijms21020654.

19. Yu T, An Q, Cao XL, Yang H, Cui J, Li ZJ, Xiao G. GOLPH3 inhibition reverses oxaliplatin resistance of colon cancer cells via suppression of $\mathrm{PI} 3 \mathrm{~K} / \mathrm{AKT} / \mathrm{mTOR}$ pathway. Life Sci. 2020;260:118294. Https://doi.org/10.1016/j.1fs.2020.118294.

20. Chen M, Lu J, Wei W, Lv Y, Zhang XQ, Yao YL, et al. Effects of proton pump inhibitors on reversing multidrug resistance via downregulating $\mathrm{V}$-ATPases/PI3K/Akt/mTOR/HIF-1 $\alpha$ signaling pathway through TSC1/2 complex and Rheb in human gastric adenocarcinoma cells in vitro and in vivo. Onco Targets Ther. 2018;11:6705-6722. Https://doi.org/10.2147/OTT.S161198.

21. Wang XH, Huang W, Liu GS, Cai WF, W Millard R, Wang YG, et al. Cardiomyocytes mediate anti-angiogenesis in type 2 diabetic rats through the exosomal transfer of miR-320 into endothelial cells. J Mol Cell Cardiol. 2014;74:139-150. Https://doi.org/10.1016/j.yjmcc.2014.05.001.

22. Li M, Lu Y, Xu YC, Wang JW, Zhang CH, Du Y, et al. Horizontal transfer of exosomal CXCR4 promotes murine hepatocarcinoma cell migration, invasion and lymphangiogenesis. Gene. 2018;676:101-109. Https://doi.org/10.1016/j.gene.2018.07.018.

23. Jiang L, Wang P, Sun YJ, Wu YJ. Ivermectin reverses the drug resistance in cancer cells through EGFR/ERK/Akt/NF- $\mathrm{BB}$ pathway. J Exp Clin Cancer Res. 2019;38(1):265. Https://doi.org/10.1186/s13046-019-1251-7.

24. Steinbichler TB, Dudás J, Skvortsov S, Ganswindt U, Riechelmann H, Skvortsova II. Therapy resistance mediated by exosomes. Mol Cancer. 2019;18(1):58. Https://doi.org/10.1186/s12943-019-0970-x.

25. Tan SM, Xia LZ, Yi P, Han YQ, Tang L, Pan Q, et al. Exosomal miRNAs in tumor microenvironment. J Exp Clin Cancer Res. 2020;39(1):67. Https://doi.org/10.1186/s13046-020-01570-6.

26. Cao C, Wang B, Tang JN, Zhao JM, Guo JC, Guo QQ, et al. Circulating exosomes repair endothelial cell damage by delivering miR-193a-5p. J Cell Mol Med. 2021;25(4):2176-2189. Https://doi.org/10.1111/jcmm.16202.

27. Fu X, Liu MJ, Qu SY, Ma JQ, Zhang YM, Shi TT, et al. Exosomal microRNA-32-5p induces multidrug resistance in hepatocellular carcinoma via the PI3K/Akt pathway. J Exp Clin Cancer Res. 2018;37(1):52. Https://doi.org/10.1186/s13046-018-0677-7. 
28. Zhu XL, Shen HL, Yin XM, Yang ML, Wei H, Chen Q, et al. Macrophages derived exosomes deliver miR-223 to epithelial ovarian cancer cells to elicit a chemoresistant phenotype. J Exp Clin Cancer Res. 2019;38(1):81. Https://doi.org/10.1186/s13046-019-1095-1.

29. Wang M, Qiu R, Yu SR, Xu XY, Li G, Gu RM, et al. Paclitaxel-resistant gastric cancer MGC-803 cells promote epithelial-to-mesenchymal transition and chemoresistance in paclitaxel-sensitive cells via exosomal delivery of miR-155-5p. Int J Oncol. 2018;54:326-338. Https://doi.org/10.3892/ijo.2018.4601.

30. Lin H, Zhang L, Zhang CH, Liu PP. Exosomal MiR-500a-3p promotes cisplatin resistance and stemness via negatively regulating FBXW7 in gastric cancer. J Cell Mol Med. 2020;24(16):8930-8941. Https://doi.org/10.1111/jcmm.15524.

31. Yang S, Gu YL, Wang GJ, Hu QZ, Chen SX, Wang Y, Zhao MF. HMGA2 regulates acute myeloid leukemia progression and sensitivity to daunorubicin via Wnt/ $\beta$-catenin signaling. Int J Mol Med. 2019;44(2):427-436. Https://doi.org/10.3892/ijmm.2019.4229.

32. Yang Y, Zhang P, Zhao YF, Yang J, Jiang GN, Fan J. Decreased MicroRNA-26a expression causes cisplatin resistance in human non-small cell lung cancer. Cancer Biol Ther. 2016;17(5):515-525. Https://doi.org/10.1080/15384047.2015.1095405.

33. Yang XY, Zhao Q, Yin HL, Lei XY, Gan RL. MiR-33b-5p sensitizes gastric cancer cells to chemotherapy drugs via inhibiting HMGA2 expression. J Drug Target. 2017;25(7):653-660. Https://doi.org/10.1080/1061186X.2017.1323220.

34. Wang Y, Chen FQ, Zhao M, Yang Z, Zhang SQ, Ye LH, et al. MiR-107 suppresses proliferation of hepatoma cells through targeting HMGA2 mRNA 3'UTR. Biochem Biophys Res Commun. 2016;480(3):455-460. Https://doi.org/10.1016/j.bbrc.2016.10.070.

35. Liu XZ, Yidayitula Y, Zhao H, Luo Y, Ma XQ, Xu MH. LncRNA LINC00152 promoted glioblastoma progression through targeting the miR-107 expression. Environ Sci Pollut Res Int. 2018;25(18):17674-17681. Https://doi.org/10.1007/s11356-018-1784-x.

36. Mansoori B, Mohammadi A, Ditzel HJ, Duijf PHG, Khaze V, Gjerstorff MF, Baradaran B. HMGA2 as a Critical Regulator in Cancer Development. Genes (Basel). 2021;12(2):269. Https://doi.org/10.3390/genes12020269.

37. Tan L, Wei XP, Zheng LX, Zeng JC, Liu HB, Yang SJ, Tan H. Amplified HMGA2 promotes cell growth by regulating Akt pathway in AML. J Cancer Res Clin Oncol. 2016;142(2):389-399. Https://doi.org/10.1007/s00432-015-2036-9.

38. Wang YD, Mao JD, Wang JF, Xu MQ. MiR-590 suppresses proliferation and induces apoptosis in pancreatic cancer by targeting high mobility group A2. Technol Cancer Res Treat. 2020;19:1533033820928143. Https://doi.org/10.1177/1533033820928143.

39. Robey RW, Pluchino KM, Hall MD, Fojo AT, Bates SE, Gottesman MM. Revisiting the role of $\mathrm{ABC}$ transporters in multidrug-resistant cancer. Nat Rev Cancer. 2018;18(7):452-464. Https://doi.org/10.1038/s41568-018-0005-8. 
40. Song L, Zhou ZG, Gan YB, Li P, Xu Y, Zhang ZH, et al. Long noncoding RNA OIP5-AS1 causes cisplatin resistance in osteosarcoma through inducing the LPAAT $\beta /$ PI3K/AKT/mTOR signaling pathway by sponging the miR-340-5p. J Cell Biochem. 2019;120(6):9656-9666. Https://doi.org/10.1002/jcb.28244.

41. Ma Q, Chang ZH, Wang W, Wang BM. Rapamycin-mediated mTOR inhibition reverses drug resistance to adriamycin in colon cancer cells. Hepatogastroenterology. 2015;62(140):880-6.

42. Wang SF, Chou YC, Mazumder N, Kao FJ, Nagy LD, Guengerich FP, et al. 7-Ketocholesterol induces P-glycoprotein through PI3K/mTOR signaling in hepatoma cells. Biochem Pharmacol. 2013;86(4):548-560. Https://doi.org/10.1016/j.bcp.2013.06.006.

\begin{abstract}
Abbreviations
GC:gastric cancer; TEM:transmission electron microscopy; DLS:dynamic light scattering; RT-qPCR:real-time quantitative PCR; DDP:cisplatin; HMGA2:high mobility group A2; P-gp:P-glycoprotein; Gluc:Gaussia luciferase; SeAP:secreted alkaline phosphatase; MDR1:multidrug resistance protein 1; ABC:ATP-binding cassette; NC:negative control.
\end{abstract}

\title{
Declarations
}

\section{Ethics approval and consent to participate}

Not applicable.

\section{Consent for publication}

Not applicable.

\section{Availability of data and materials}

All data generated or analysed during this study are included in this published article and its supplementary information files.

\section{Competing interests}

The authors declare that they have no competing interests.

\section{Funding}

This work was supported in part by the grants from the Colleges and Universities Key Scientific Research Project Plan Basic Research Special of Henan Province (Grant number 19zx009), Science and Technology Project for Tackling Key Problems of Henan Province (Grant number 182102311172), and Doctoral Research Startup Fund of Henan University of Traditional Chinese Medicine (Grant number RSBSJJ2019-26). 


\section{Authors' contributions}

LJ and WHR designed the research studies. LJ, YZ, LHG and CYL performed the research. LJ interpreted the data. LJ and WHR cowrote the manuscript. All authors read and approved the final manuscript.

\section{Acknowledgements}

Not applicable.

\section{Authors' information}

${ }^{1}$ Henan University of Traditional Chinese Medicine, 156 Jinshui East Road, Zhengzhou 450046, China.

${ }^{2}$ Department of Clinical Laboratory, The First Affiliated Hospital of Henan University of Traditional Chinese Medicine, 19 Renmin Road, Zhengzhou 450000, China. 


\section{Figures}
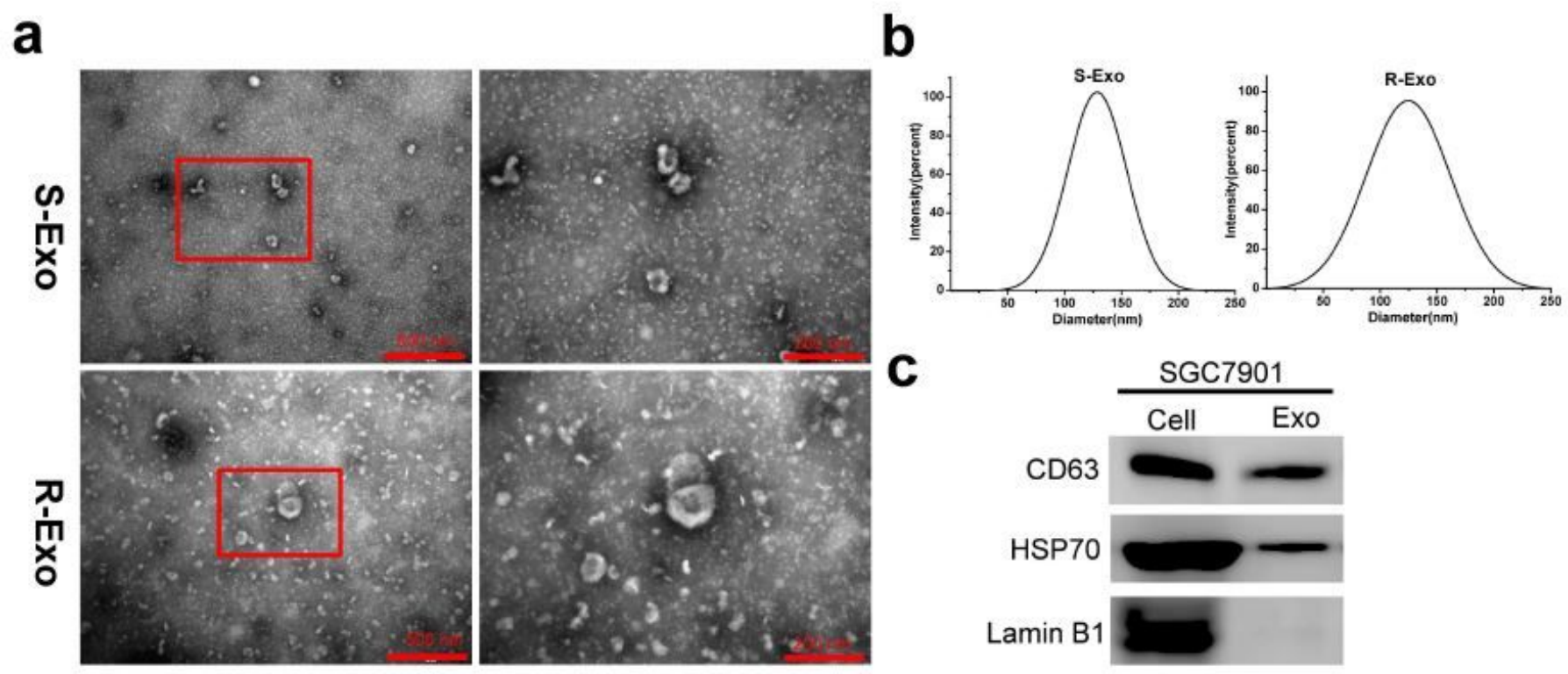

C

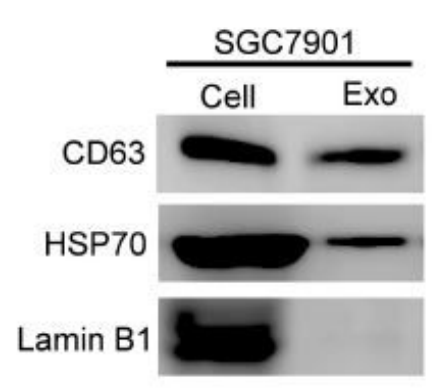

Figure 1

Characteristics of exosomes drived from SGC-7901 and SGC-7901/5-FU GC cells. a The transmission electron micrograph showed round-shaped vesicles with bilayered membranes ranging from $30 \mathrm{~nm}$ to $180 \mathrm{~nm}$ in diameter released by SGC-7901 (S-Exo) and SGC-7901/5-FU (R-Exo) cells. Scale bar $=500 \mathrm{~nm}$ and $200 \mathrm{~nm}$, respectively. b Dynamic light scattering analysis (DLS) indicated that the dominant size of S- and R-Exo was about $120 \mathrm{~nm}$. c The positive markers of exosomes, CD63 and HSP70, were detected in S- and R-Exo by Western blot. 

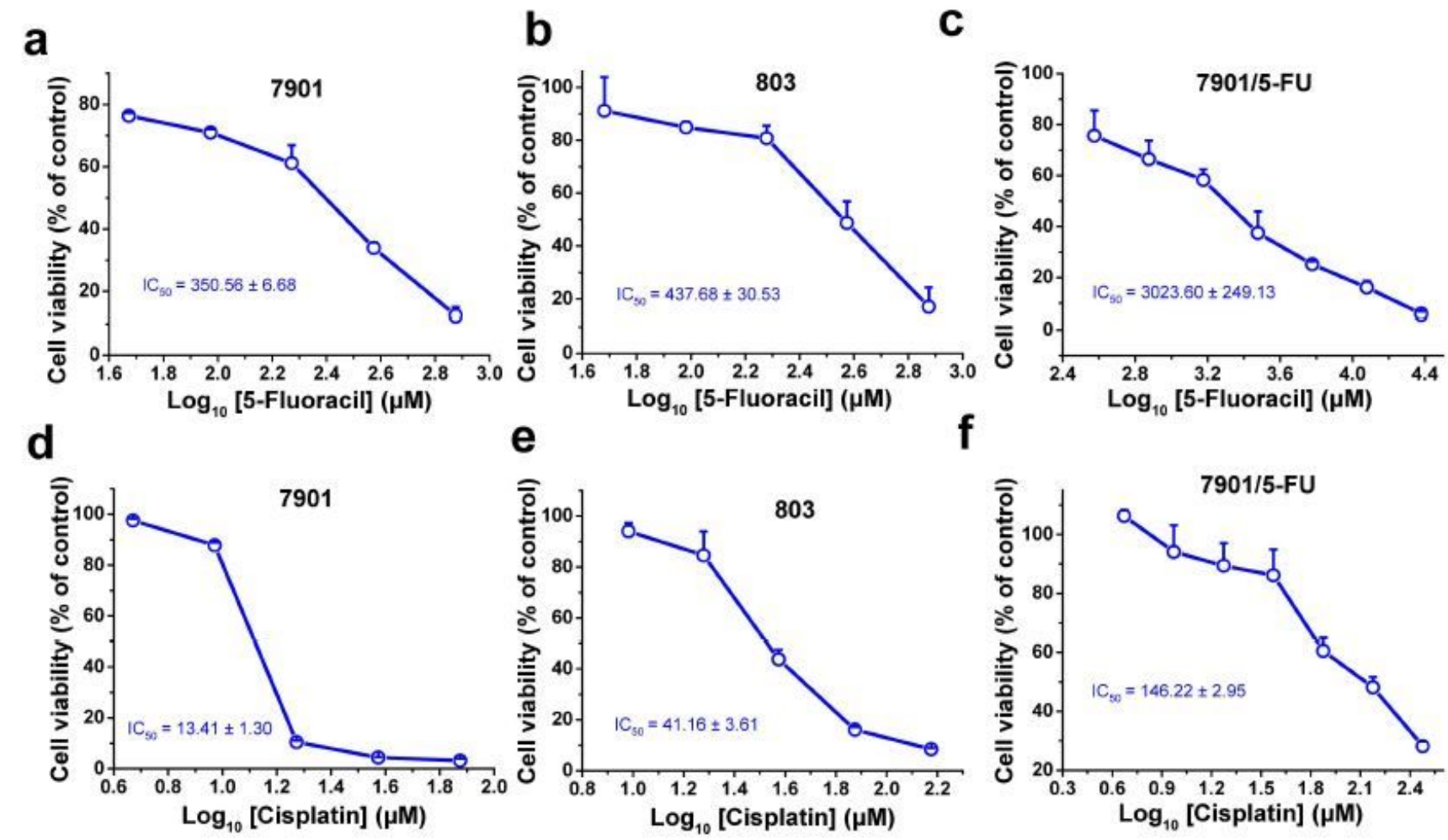

\section{Figure 2}

The sensitivity of GC cells to the chemotherapy drugs 5-FU and DDP. The cell viability of SGC-7901 (a and d), MGC-803 (b and e) sensitive cell strains and SGC-7901/5-FU ( $c$ and f) resistant cell strains after treated with $5-F U$ for $48 \mathrm{~h}(\mathrm{a}, \mathrm{b}, \mathrm{c})$ and $\operatorname{DDP}(\mathrm{d}, \mathrm{e}, \mathrm{f})$ for $24 \mathrm{~h}$, respectively. Cell viability was determined by MTT assay. Cells treated with vehicle serve as a blank control. All experiments were conducted in quintuplicates and data were expressed as the mean $\pm \operatorname{SD}(n=5)$
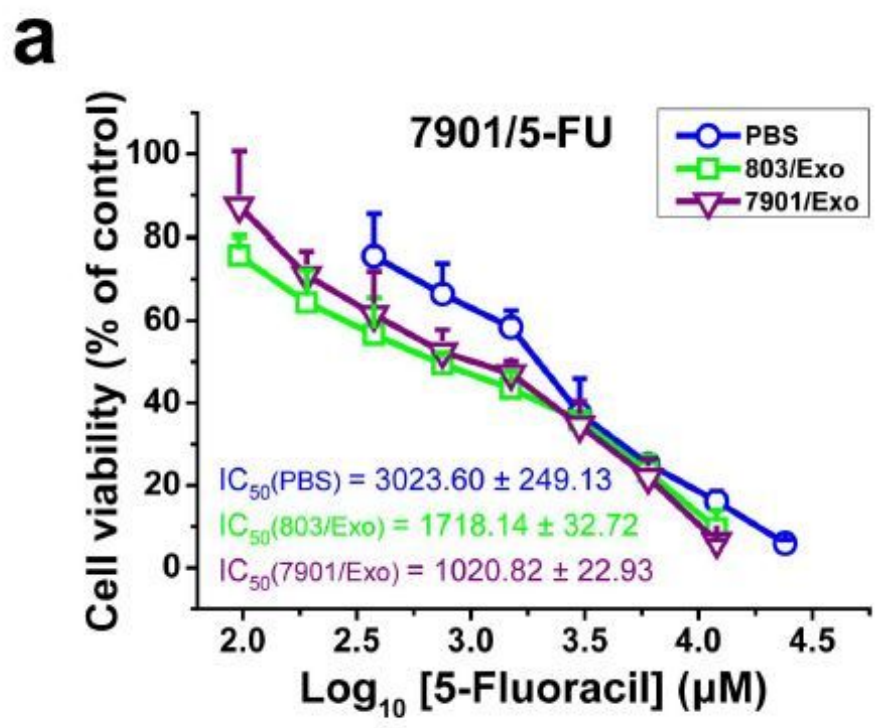

b

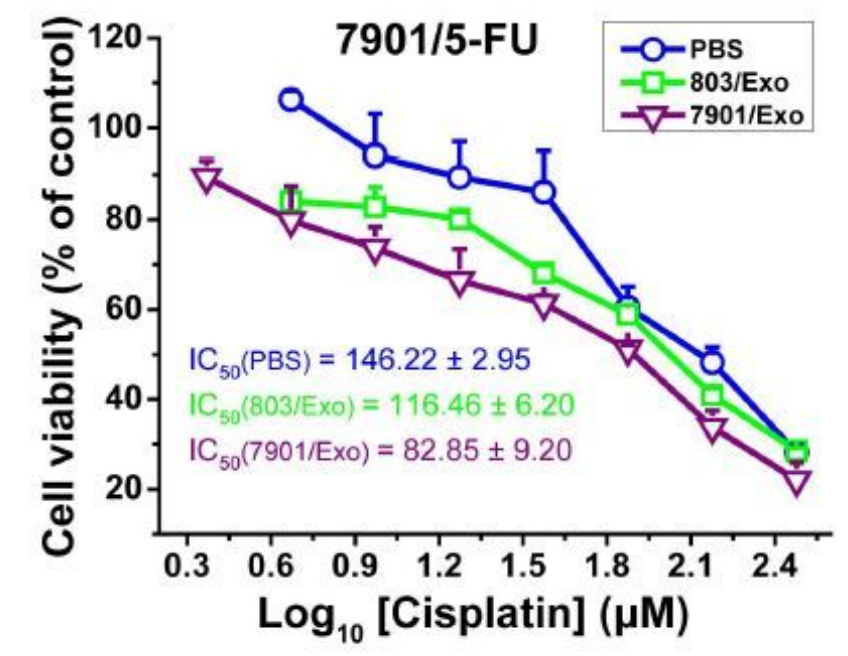




\section{Figure 3}

The exosomes isolated from sensitive GC cells increased drug sensitivity of drug-resistant GC cells. The cell viability of SGC-7901/5-FU cells after treated with 5-FU (a) or DDP (b) with or without the exosomes isolated from SGC-7901 or MGC-803 cells for 48 or $24 \mathrm{~h}$, respectively. Cell viability was determined by MTT assay. Cells treated with vehicle serve as a blank control. Abbreviations: Exo, exosomes. All experiments were conducted in quintuplicates and data were expressed as the mean $\pm S D(n=5)$.

a
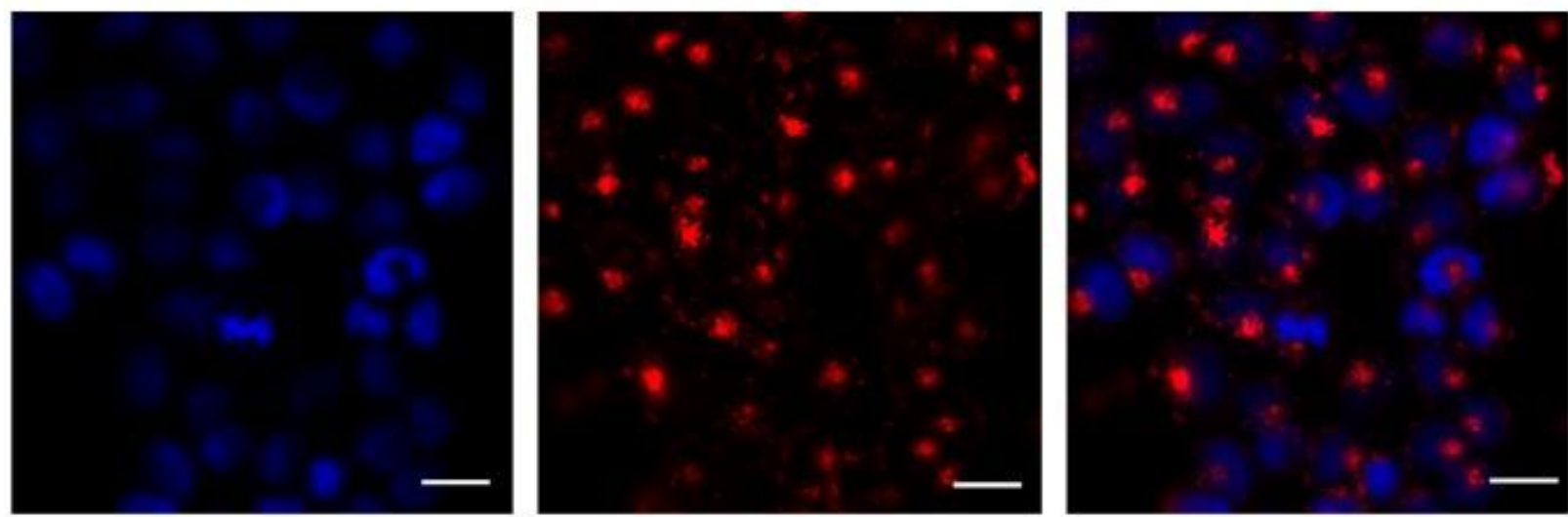

b

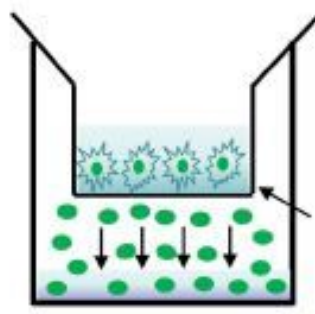

$0.4 \mu \mathrm{m}$ pore

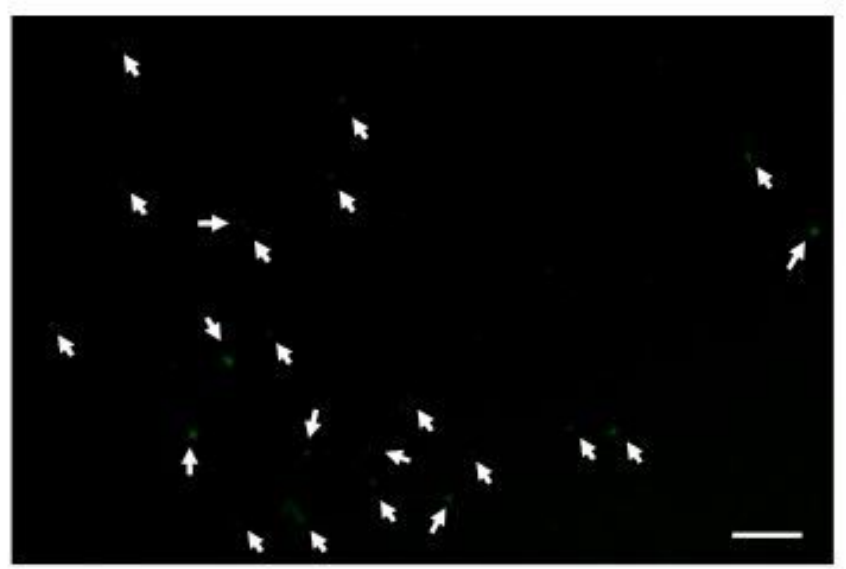

C

\section{cell coculture}
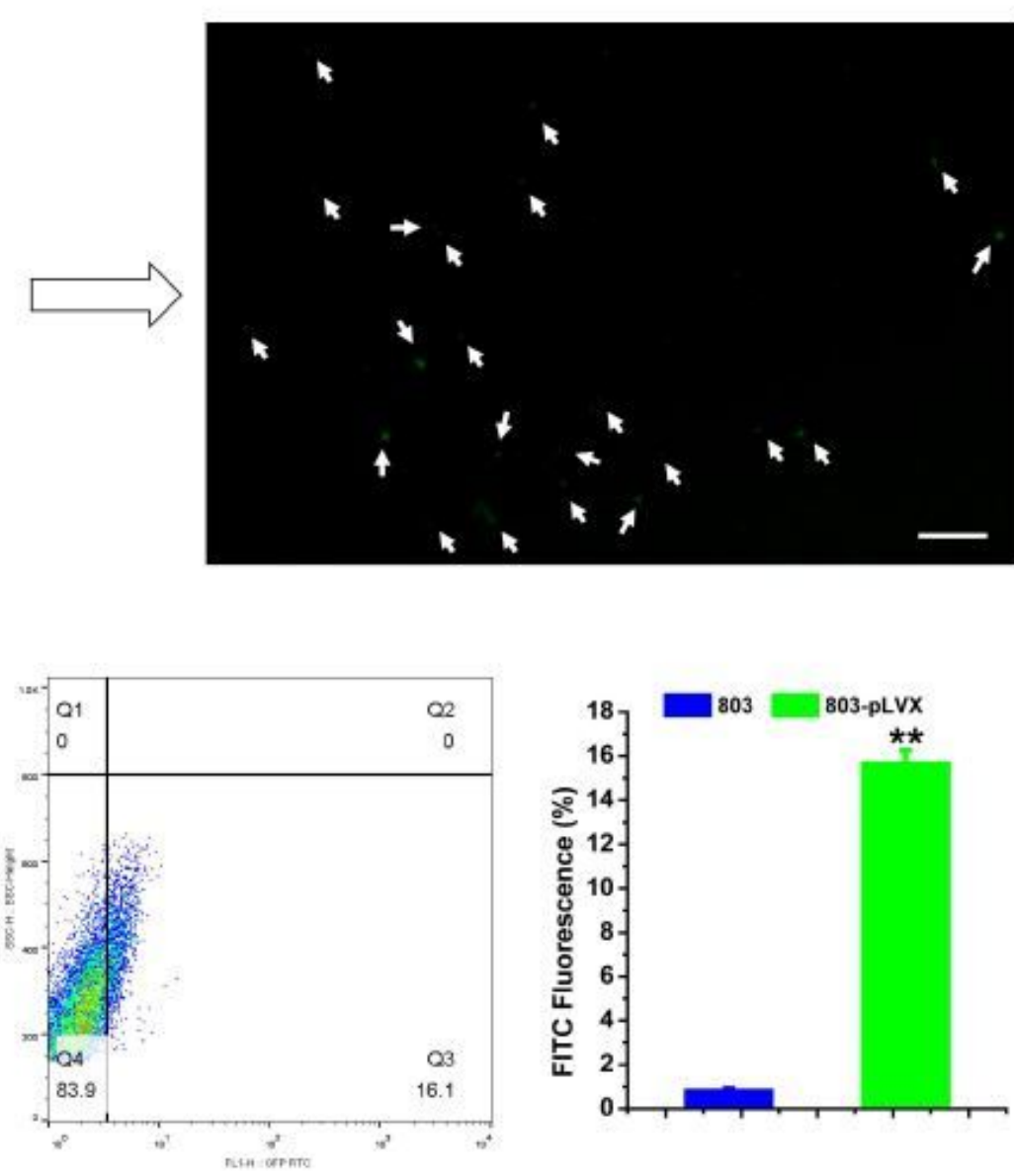

Figure 4 
Exosomes derived from sensitive GC cells were taken up by SGC-7901/5-FU cells. a Confocal microscopy showed exosome internalization by SGC-7901/5-FU recipient cells after co-incubation with PKH26-labeled SGC-7901 exosomes. Red: exosomes stained with PKH26, blue: DAPI. Scale Bars $=20 \mu \mathrm{m}$. b The MGC803-pLVX stable cells were placed in the upper chamber and coincubated with SGC-7901/5-FU cells seeded in the lower chamber in a coculture system with a $0.4 \mu \mathrm{m}$ pore membrane. Green fluorescence were observed in the SGC-7901/5-FU recipient cells under the fluorescence microscope. Scale Bars = 35 $\mu \mathrm{m}$. c The percentage of green fluorescence signals in SGC-7901/5-FU resistant GC cells were determined by flow cytometry. Data were expressed as the mean $\pm S D(n=3)$. Statistical significances were determined using one-way ANOVA followed by Dunnett's test. ${ }^{*} \mathrm{P}<0.01$, compared with the group of MGC-803 cells.
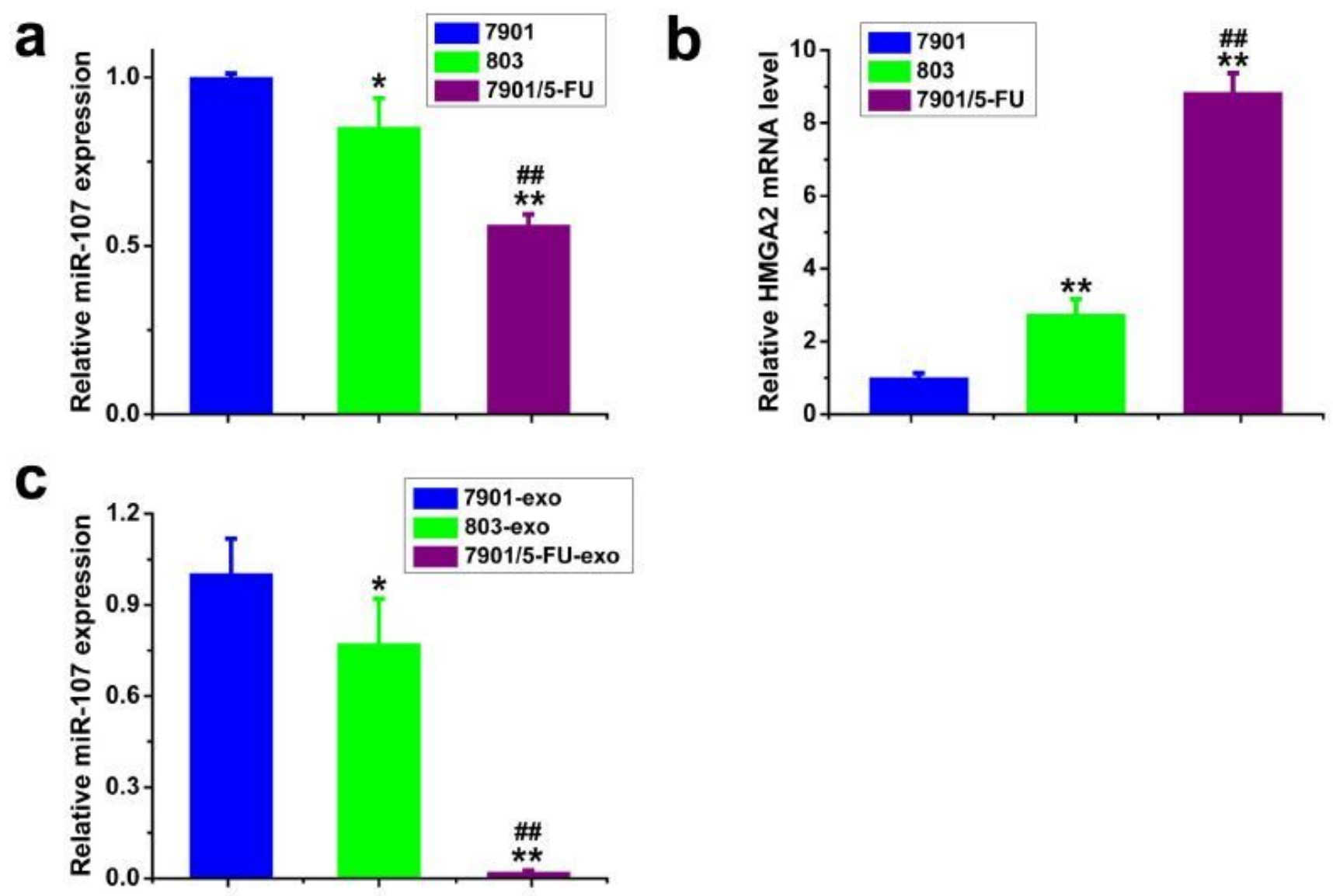

\section{Figure 5}

The expression levels of miR-107 and HMGA2 in SGC-7901, MGC-803 and SGC-7901/5-FU cells and exosomes were detected by qPCR. the expression levels of miR-107 (a) and HMGA2 (b) in SGC-7901, MGC-803 sensitive and SGC-7901/5-FU resistant cells; the expression levels of miR-107 (c) in SGC-7901, MGC-803 sensitive and SGC-7901/5-FU resistant exosomes. mRNA and miRNA levels were determined by qPCR using GAPDH and U6 as the internal control, respectively. Data were expressed as the mean \pm SD ( $n$ = 3). Statistical significances were determined using one-way ANOVA followed by Dunnett's test. *P< 
0.05, **P < 0.01, compared with SGC-7901 cells/exosomes; \#\#P < 0.01, compared with MGC-803 cells/exosomes.

a

HMGA2-WT 5'- gtcTAGTACTTATTAC-ATGCTGCt -3'

hsa-miR-107 3'- acuAUCGGGACAUGUUACGACGa -5'

HMGA2-MUT 5'- gtcTAGTACTTATTAC-TACGACGt -3'

b

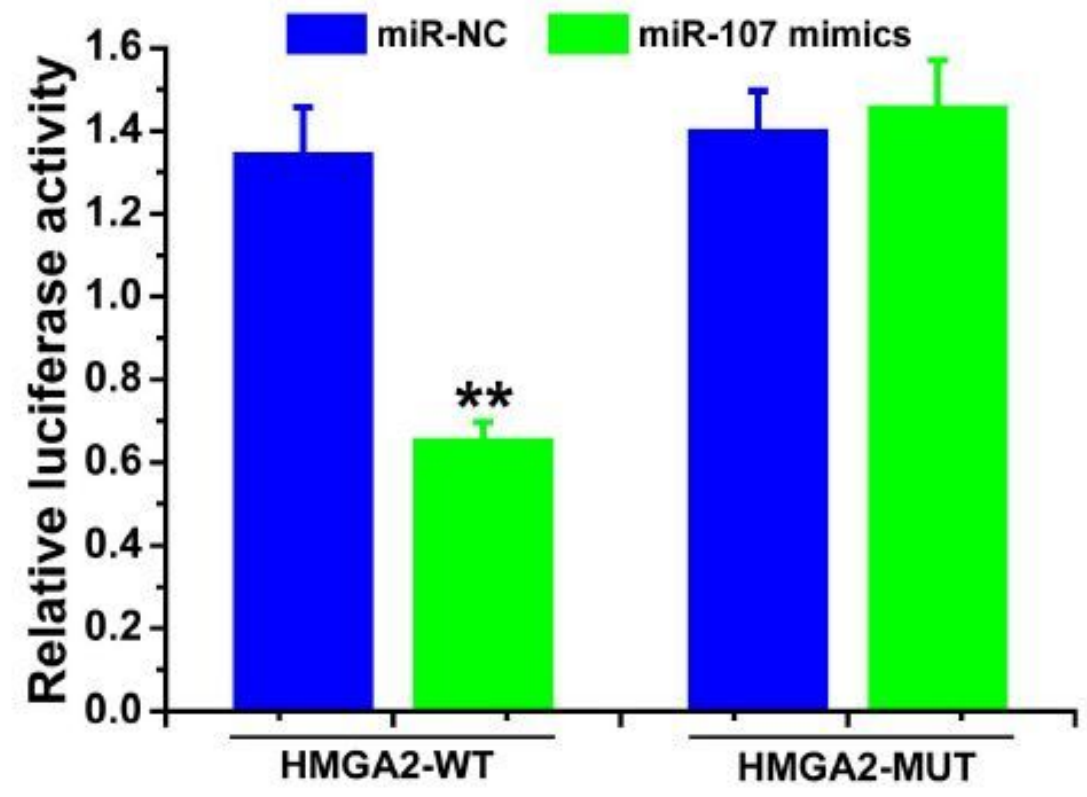

Figure 6

Downstream target molecular of miR-107 was HMGA2. a Predicted binding sites of miR-107 in HMGA2 3囚-UTR. b Plasmid vectors of human HMGA2 3'-UTR or its mutation were transfected into 293T cells together with miR-107 mimics or NC. Data were expressed as fold change of the luciferase activity over the control from the NC group (mean $\pm S D, n=3$ ). Statistical significances were determined using oneway ANOVA followed by Dunnett's test. ${ }^{*} \mathrm{P}<0.01$, compared with respective controls. 

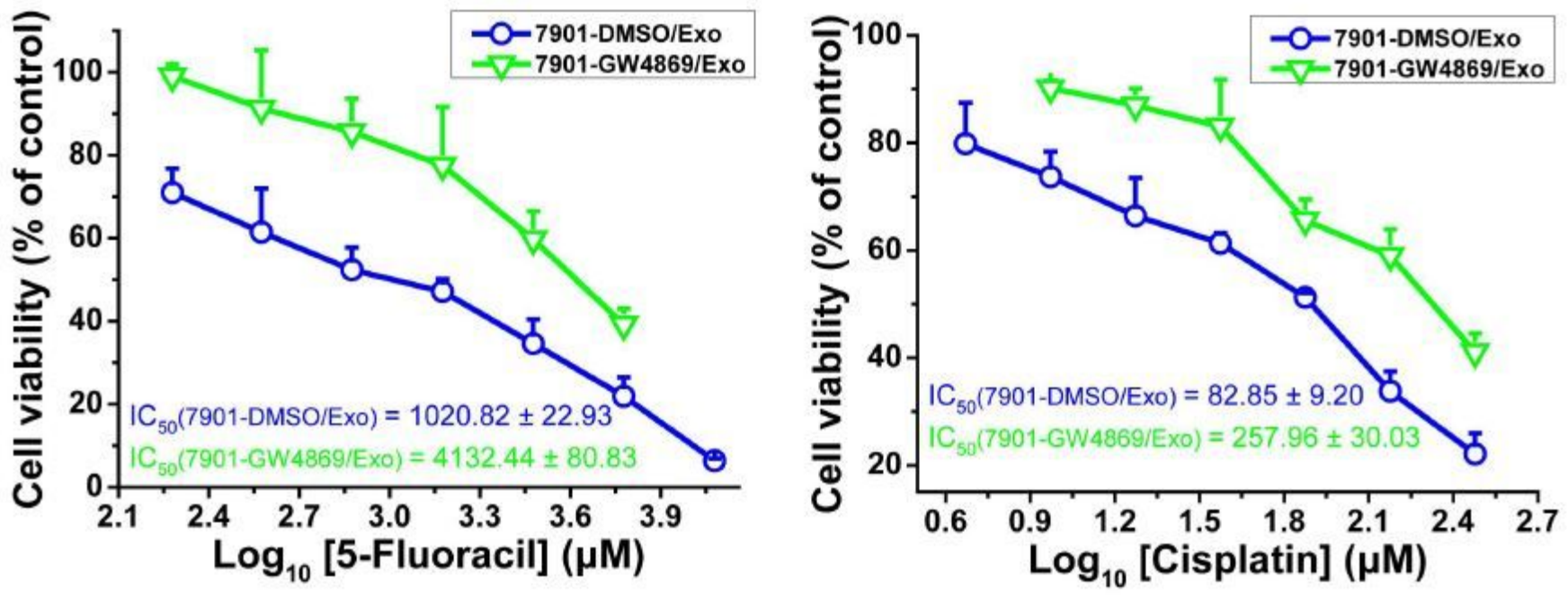

Figure 7

Exosomes transfer increased drug sensitivity of SGC-7901/5-FU cells. The cell viability of SGC-7901/5-FU cells after treated with 5-FU (a) or DDP (b) combined with exosomes extracted from SGC-7901 cells (with or without the exosome inhibitor GW4869 treatment) for 48 or $24 \mathrm{~h}$, respectively. Cell viability was determined by MTT assay. Cells treated with vehicle serve as a blank control. Abbreviations: Exo, exosomes. All experiments were conducted in quintuplicates and data were expressed as the mean \pm SD $(n=5)$.

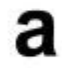

b
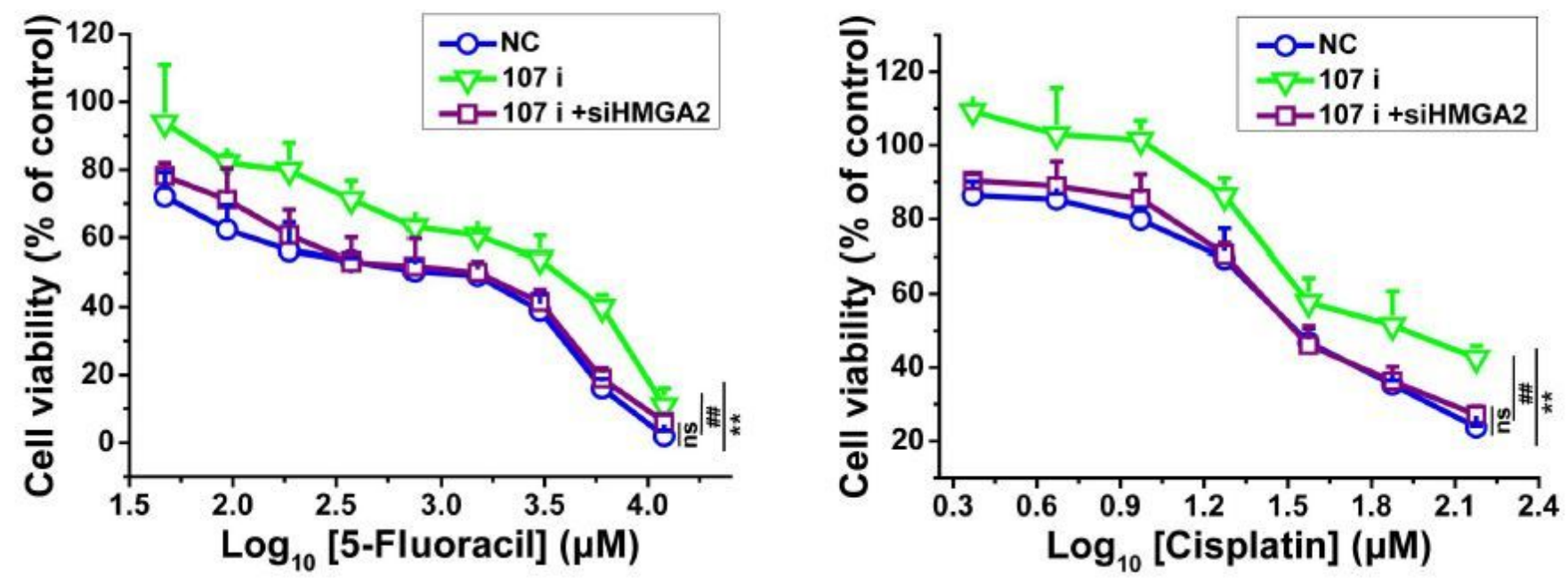

Figure 8 
SGC-7901-secreted exosomal miR-107 reversed drug resistance of SGC-7901/5-FU cells by inhibiting HMGA2. The SGC-7901/5-FU cells were transfected with miRNA-107 inhibitor, co-transfection with miRNA-107 inhibitor and siRNA traget for HMGA2 and miRNA-107 inhibitor/siHMGA2 negative control for $24 \mathrm{~h}$, and the cell viability of SGC-7901/5-FU cells after treated with different concentrations of 5-FU (a) or DDP (b) combined with exosomes extracted from SGC-7901 cells for 48 or $24 \mathrm{~h}$, respectively. Cell viability was determined by MTT assay. Cells treated with vehicle serve as a blank control. Abbreviations: Exo, exosomes. All experiments were conducted in quintuplicates and data were expressed as the mean \pm SD $(n=5)$. Statistical significances were determined using one-way ANOVA followed by Dunnett's test. **P< 0.01 , compared with negative control transfection group; \#\#P $<0.01$, compared with miRNA-107 inhibitor/siHMGA2 co-transfection group; ns, no significance $(P>0.05)$, comparison between negative control transfection group and miRNA-107 inhibitor/siHMGA2 co-transfection group.

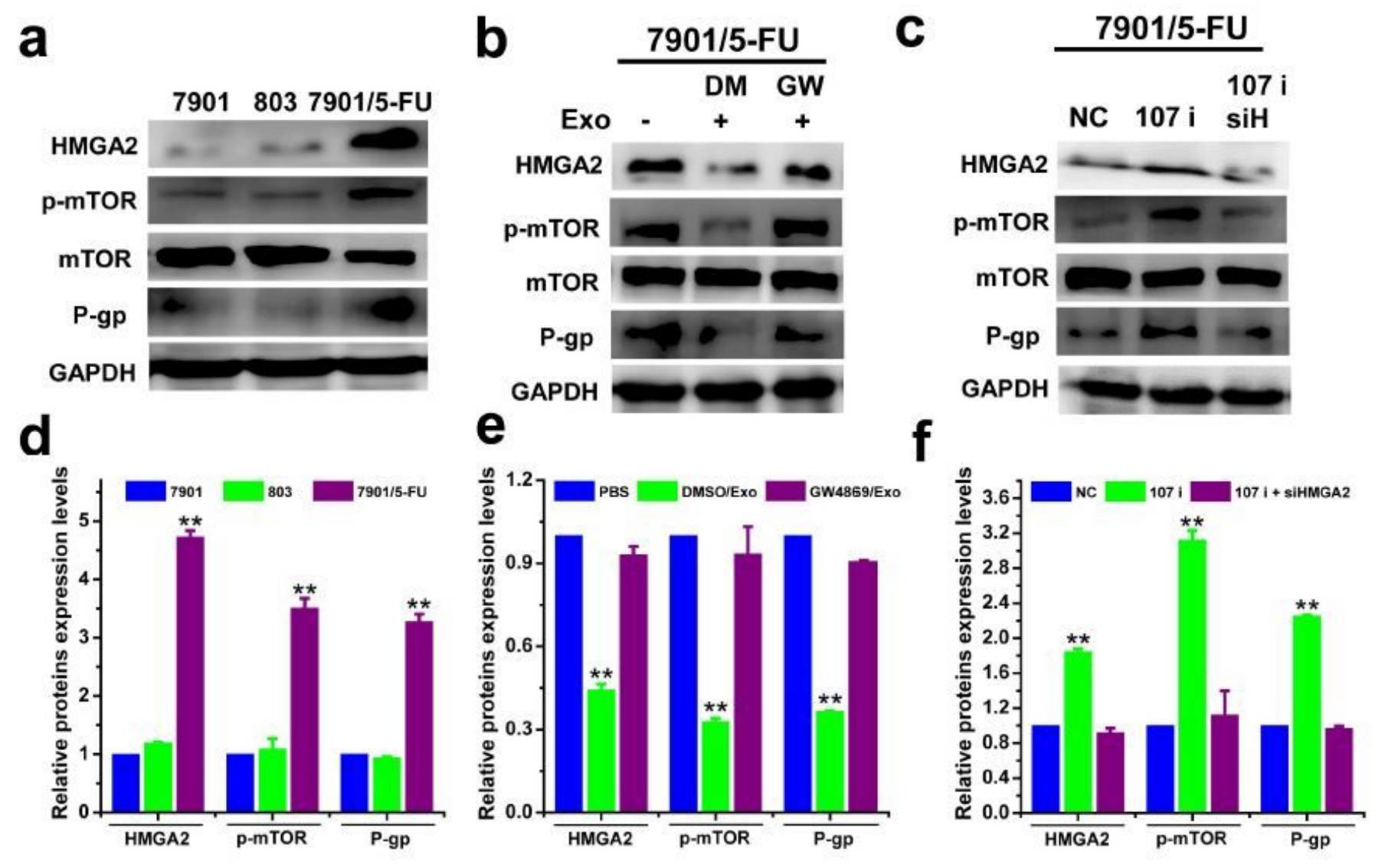

Figure 9

Exosomal miR-107 reversed drug resistance of SGC-7901/5-FU cells by downregulating HMGA2/mTOR/P-gp pathway. The protein expression levels of HMGA2, p-mTOR/mTOR, P-gp (a-c) and corresponding quantitative analysis (d-f) of SCG7901, MGC-803 and SCG7901/5-FU cells treated with or without exosomal inhibitor GW4869 and transfected with miR-107 inhibitor, co-transfected with miRNA107 inhibitor/siHMGA2 or negative control were determined. The protein expression levels were detected by western blotting analysis using GAPDH as internal control. Cells treated with vehicle, or transfected 
with control miRNA or siRNA serve as control. Abbreviations: Exo, exosome; DM, DMSO; GW, GW4869; NC, negative control. Data in a-c are the representative of two independent experiments. Statistical significances in d-f were determined using one-way ANOVA followed by Dunnett's test. ${ }^{*} \mathrm{P}<0.01$, compared with the respective controls or sensitive cells.

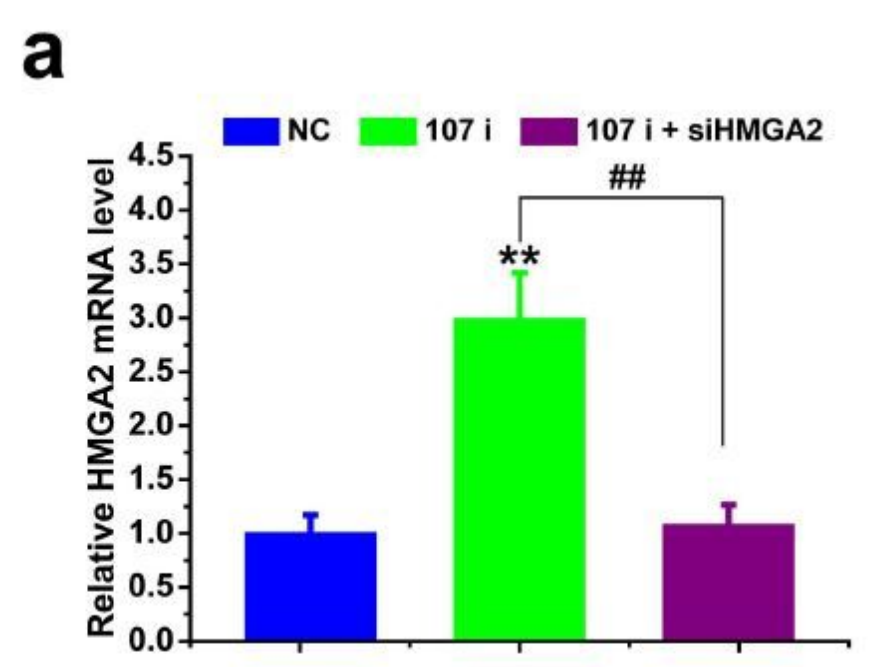

\section{b}

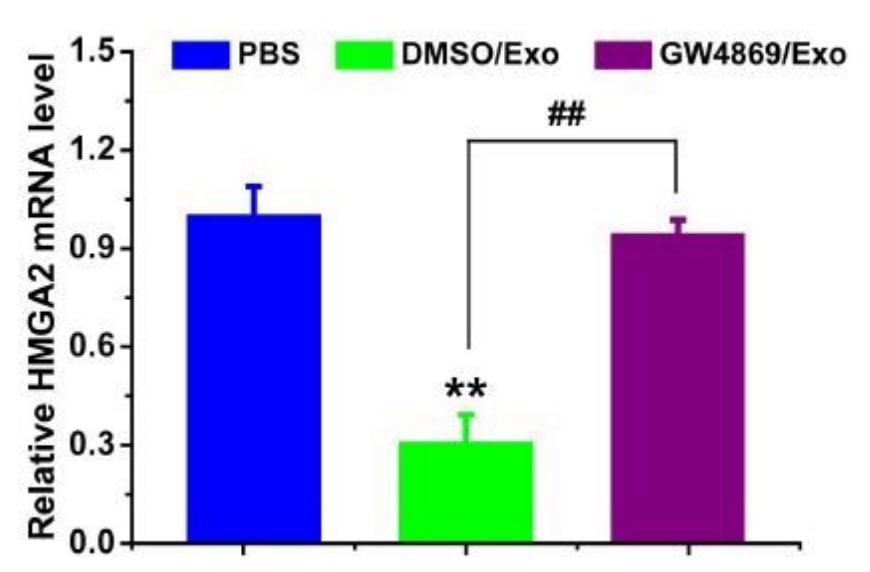

Figure 10

Exosomal miR-107 increased drug sensitivity of SCG-7901/5-FU cells by regulating the mRNA level of HMGA2. mRNA level of HMGA2 of SCG-7901/5-FU cells transfected with miR-107 inhibitor, co-transfected with miRNA-107 inhibitor/siHMGA2 or negative control (a) and treated with or without exosomal inhibitor GW4869 (b) were detected. mRNA levels were determined by qPCR using GAPDH as the internal control. Cells treated with vehicle, or transfected with control miRNA or siRNA serve as control. Abbreviations: Exo, exosome; DM, DMSO; GW, GW4869; NC, negative control. Data were expressed as the mean \pm SD $(n=3)$. Statistical significances were determined using one-way ANOVA followed by Dunnett's test. ${ }^{*} \mathrm{P}<0.01$, compared with the respective controls; \#\#P<0.01, comparison between the two columns. 
Donor cells (sensitive GC cells)

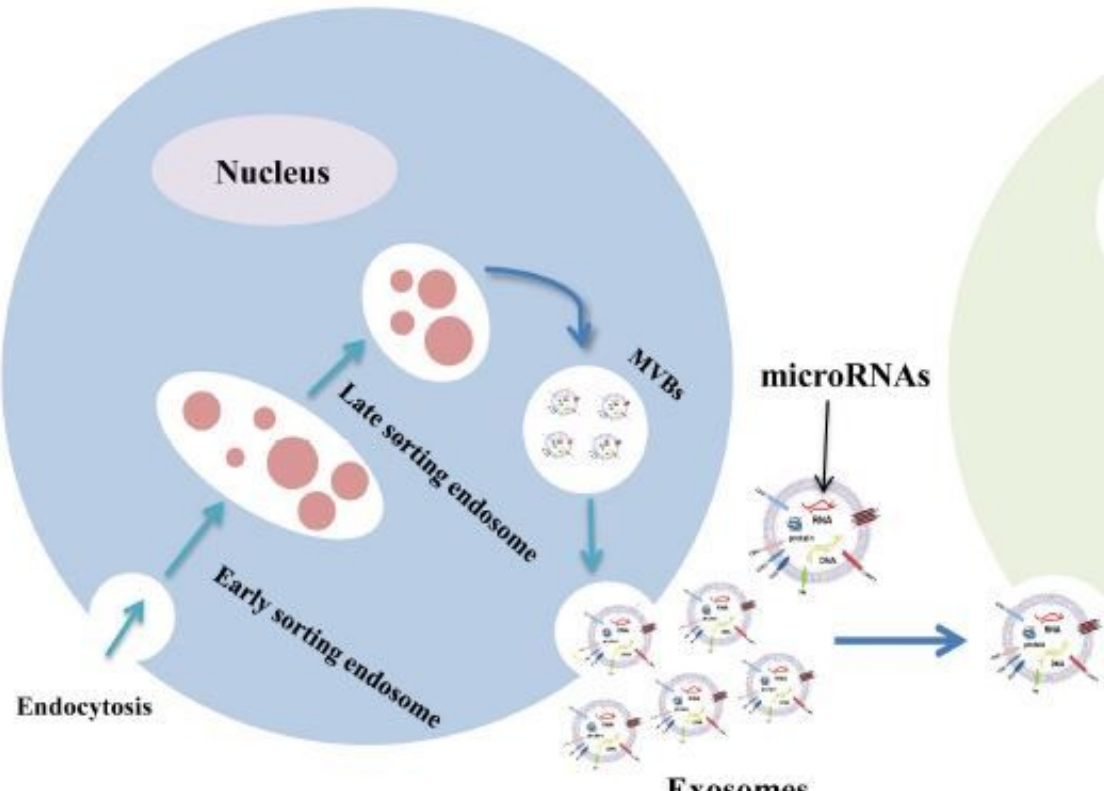

Exosomes
Recipient cells (resistant GC cells)
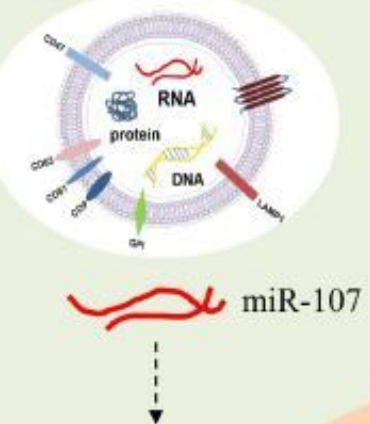

HMGA2

\section{Exo-miR-107 $\longrightarrow$ HMGA2 $\longrightarrow$ p-mTOR $\longrightarrow$ P-gp $\longrightarrow$ Reverse drug resistance}

\section{Figure 11}

The possible mechanism of exosomal miR-107 reversed chemotherapeutic drug resistance of SGC7901/5-FU cells. exosomal miR-107 transmitted from sensitive GC cells to recipient resistant GC cells, and improved drug sensitivity of SGC-7901/5-FU cells through inhibiting HMGA2/mTOR/P-gp signal. 